\title{
Conformational switch driven membrane pore formation by Mycobacterium secretory protein MPT63 induces macrophage cell death
}

Achinta Sannigrahi ${ }^{1 \#}$, Indrani Nandi ${ }^{1,2 \#}$, Sayantani Chall ${ }^{1 \#}$, Junaid Jibran Jawed ${ }^{3}$, Animesh Halder $^{4}$, Subrata Majumdar ${ }^{3}$, Sanat Karmakar ${ }^{4}$, Krishnananda Chattopadhyay $^{1,2^{*}}$

${ }^{1}$ Structural Biology \& Bio-Informatics Division, CSIR-Indian Institute of Chemical Biology, 4, Raja S. C. Mallick Road, Kolkata 700032, India

${ }^{2}$ Academy of Scientific and Innovative Research (AcSIR), Ghaziabad 201002, India

${ }^{3}$ Department of Molecular Medicine, Bose Institute, Kolkata, India

${ }^{4}$ Department of Physics, Jadavpur University, 188, Raja S. C. Mallick Road, Kolkata 700032, India

*Corresponding author: email: krish@iicb.res.in

\# contributed equally 


\section{Materials and methods:}

Materials. Chloroauric acid $\left(\mathrm{HAuCl}_{4}\right)$ was obtained from Spectrochem. 1,2Dioleoylphosphotidyl choline (DOPC) and 1,2-Dioleoylphosphatidylglycerol (DOPG) were purchased from Avanti Polar Lipids Inc. DiIC-18 dye was obtained from Invitrogen and acrylamide from Sigma-Aldrich. All other necessary chemicals were obtained from Aldrich and Merck. All the buffer and aqueous solutions were prepared using millipore water freshly prepared prior to every experiment.

Expression and purification of MPT63. pQE30 containing the wild type MPT63 gene was transformed into E. coli XL1-Blue cells. Single colonies of these transformed strains were grown aerobically at $37{ }^{\circ} \mathrm{C}$ in an LB medium containing ampicillin and induced with $1 \mathrm{mM}$ IPTG for 4 $\mathrm{h}$ when the O.D. of the medium reaches 0.5 at $600 \mathrm{~nm}$. Cells were harvested by centrifugation at $8000 \mathrm{rpm}$ for $15 \mathrm{~min}$ at $4{ }^{\circ} \mathrm{C}$ and re-suspended in $40 \mathrm{~mL}$ of sonication buffer containing $50 \mathrm{mM}$ potassium phosphate, $300 \mathrm{mM} \mathrm{KCl}, 10 \mathrm{mM}$ imidazole at $\mathrm{pH}$ 7.4. Cells were subjected to one cycle of freezing followed with thawing and then lysis by sonication with $1 \mathrm{mM}$ PMSF. Cell lysates were then centrifuged at $12500 \mathrm{rpm}$ for $45 \mathrm{~min}$ at $4{ }^{\circ} \mathrm{C}$. Supernatants were mixed with 2 $\mathrm{mL}$ of Ni-NTA agarose resin (Qiagen), previously equilibrated in sonication buffer, and stirred at $4{ }^{\circ} \mathrm{C}$ for $1 \mathrm{~h}$. The protein and resin slurry were then loaded into a column and washed with 10 volumes of sonication buffer followed by 10 volumes of wash buffer $(50 \mathrm{mM}$ potassium phosphate, $300 \mathrm{mM} \mathrm{KCl,} 20 \mathrm{mM}$ imidazole, $\mathrm{pH}$ 7.8). Protein was eluted in the same buffer with a gradient of 20 to $500 \mathrm{mM}$ imidazole. The collected fractions were then analyzed by SDSPAGE. Protein containing fractions were pooled and dialyzed overnight against Resource Q start buffer (30 mM Tris-HCl, $100 \mathrm{mM} \mathrm{KCl,} \mathrm{pH} \mathrm{8.7)} \mathrm{and} \mathrm{then} \mathrm{applied} \mathrm{to} \mathrm{a} \mathrm{Resource} \mathrm{Q} \mathrm{FPLC} \mathrm{column}$ pre-equilibrated with the same buffer. The column was washed with 20 volumes of the same buffer, and the protein was eluted with a 0 to $500 \mathrm{mM} \mathrm{KCl}$ gradient. Fractions containing purified protein as assessed by SDS-PAGE (purity > 90\%), were dialyzed against $20 \mathrm{mM}$ sodium phosphate buffer $\left(\mathrm{pH}\right.$ 7.4) and stored at $-20{ }^{\circ} \mathrm{C}$ until required. Site-directed mutagenesis was done using a Quick Change Lighting site-directed mutagenesis kit (Agilent Technologies) for W26F. The mutations were verified by DNA sequencing. ${ }^{1}$

Expression and purification of $\alpha$-synuclein. Recombinant human $\alpha$-synuclein ( $\alpha$-syn) was expressed in E. coli BL21 (DE3) strain transformed with pRK172 $\alpha$-syn plasmid. The expression 
was induced using $1 \mathrm{mM}$ IPTG. The cultures were incubated at $37{ }^{\circ} \mathrm{C}$ in an $\mathrm{LB}$ medium containing ampicillin with shaking at $180 \mathrm{rpm}$ for $4 \mathrm{~h}$ after addition of IPTG. Cells were then harvested by centrifugation at $8000 \mathrm{rpm}$ for $15 \mathrm{~min}$ at $4{ }^{\circ} \mathrm{C}$, after the O.D. of the medium reached 0.5 at $600 \mathrm{~nm}$. The cell pellets were then re-suspended in sonication buffer (10 mM Tris, $\mathrm{pH} \mathrm{7.4)}$ and lysed by repeated sonication with $1 \mathrm{mM}$ phenylmethylsulfonyl fluoride (PMSF). Cell lysates were then centrifuged at $14000 \mathrm{rpm}$ for $30 \mathrm{~min}$ at $4{ }^{\circ} \mathrm{C}$ to remove cell debris. The supernatant was brought to $50 \%$ saturation with addition of ammonium sulphate. The solution was centrifuged at $30000 \mathrm{rpm}$ for $1 \mathrm{~h}$ at $4{ }^{\circ} \mathrm{C}$. The resultant pellet was dissolved in Tris buffer (10 $\mathrm{mM}, \mathrm{pH}$ 7.4) and dialyzed overnight against same buffer. The filtered protein was then injected into a DEAE anion exchange column equilibrated with Tris buffer (10 mM, pH 7.4) and eluted using a 0 to $500 \mathrm{mM} \mathrm{NaCl}$ gradient. Fractions containing $\alpha$-syn (analyzed by SDS-PAGE) were concentrated and purified using a Sephadex gel filtration column. Fractions containing $\alpha$-syn were combined and lyophilized. The protein was found to be about $95 \%$ pure by SDS-PAGE. For the sample preparations of all experiments, lyophilized protein was dissolved in sodium phosphate buffer ( $\mathrm{pH} 7.4$ ) and filtered using $0.22 \mu \mathrm{m}$ low protein binding membranes (MillexGP). This step is done to remove small amount of oligomers which can act as seeds for further aggregation. $^{2}$

Expression and purification of KMP-11. Recombinant KMP-11 constructs were expressed and purified using Ni-NTA affinity chromatography using Qiagen-supplied protocol (Qiaexpressionisttm; Qiagen) with slight modifications. $20 \mathrm{mM}$ imidazole in both lysis and wash buffers was used during cell lysis. The purified protein fractions were checked using 15\% SDSPAGE. The collected fractions containing the protein were dialyzed using $20 \mathrm{mM}$ sodium phosphate buffer at $\mathrm{pH} 7.4$ to remove excess imidazole and stored at $-20{ }^{\circ} \mathrm{C}$. $^{3}$

Synthesis and characterization of citrate stabilized gold nanoparticles. Gold nanoparticles were prepared by sodium citrate reduction of chlorauric acid $\left(\mathrm{HAuCl}_{4}\right) .10 \mathrm{~mL}$ of $3 \times 10^{-4} \mathrm{M}$ aqueous solution of $\mathrm{HAuCl}_{4}$ was heated till boiling. $900 \mu \mathrm{L}$ of $6.8 \times 10^{-2} \mathrm{M}$ sodium citrate was then added dropwise with stirring. The solution at first became colourless and afterwards began to darken with stirring. After $10 \mathrm{~min}$, the reaction was completed turning the solution into deep wine red colour. The suspension was stored at $4{ }^{\circ} \mathrm{C}$ until needed. ${ }^{4}$ 
DLS measurement showed average size of as-prepared gold nanoparticles was $16 \mathrm{~nm}$ (Figure $\mathrm{S} 1$ ). The average diameter of the citrate stabilized gold nanoparticles (ctGNP) was further confirmed from a high resolution transmission electron microscope (HR-TEM), measuring the average size around $15 \pm 3 \mathrm{~nm}$. Zeta potential value for ctGNP was $-51 \mathrm{eV}$.

Preparation of Large Unilamellar Vesicles (LUV). An appropriate quantity of lipid was transferred in chloroform $\left(25 \mathrm{mg} \mathrm{mL}^{-1}\right)$ in a $10 \mathrm{~mL}$ glass bottle. The organic solvent was removed by gently passing dry nitrogen gas. The sample was then placed in a desiccator connected to a vacuum pump for a couple of hours to remove any traces of leftover solvent. Sodium phosphate buffer $(20 \mathrm{mM}$ at $\mathrm{pH}$ 7.4) was added to the dried lipid film so that the final concentration of $10 \mathrm{mM}$ was obtained as desired. The lipid film was kept overnight with the buffer at $4{ }^{\circ} \mathrm{C}$ to ensure efficient hydration of the phospholipid heads. The hydrated lipid film was then vortexed for about 30 min producing multilamellar vesicles (MLVs). Long vortexing was required to make uniform lipid mixtures. LUVs were prepared by extruding the MLV with LiposoFast using an AVESTIN extruder. The MLV suspensions were extruded through polycarbonate membranes having pore diameters of $120 \mathrm{~nm}$. The LUVs formed (average diameter $\sim 120 \mathrm{~nm}$ ) with well-defined sizes, as measured by dynamic light scattering (DLS). The vesicle solutions were degassed prior to all measurements to remove any artifacts by air bubbles introduced into the sample during extrusion. ${ }^{5}$

Preparation of Giant Unilamellar Vesicles (GUV). GUVs were formed in $0.1 \mathrm{M}$ sucrose prepared in $1 \mathrm{mM}$ HEPES (pH 7.4) buffer using electroformation, as described by Pott et al. ${ }^{6}$ Briefly, $20 \mu \mathrm{L}$ of a $1 \mathrm{mM}$ lipid solution in chloroform were spread onto the surfaces of two conductive glasses (coated with Fluor Tin Oxide), which were then placed with their conductive sides facing each other. These droplets were allowed to dry overnight in a closed chamber containing saturated solution of $\mathrm{NaCl}$. This is to avoid complete drying of the droplets. The hydration of these droplets facilitates electroformation process. Electroformation chamber was made using Teflon spacer of thickness $\sim 2 \mathrm{~mm}$. This electro swelling chamber was filled with $0.1 \mathrm{M}$ sucrose solution and branched to an alternating power generator at $1.5 \mathrm{~V}$ and $15 \mathrm{~Hz}$ frequency during $2 \mathrm{~h}$ at room temperature $\left(22-25^{\circ} \mathrm{C}\right)$. The vesicles solution was then carefully transferred to an Eppendorf vial and kept at rest at $4{ }^{\circ} \mathrm{C}$ before use. 
Imaging of the as prepared GUVs was performed an inverted microscope (DMi8) from Leica. Observation chamber consists of a glass slide with rubber spacers. Average diameter of the GUV obtained was 10-100 $\mu \mathrm{m}$. GUV were diluted in 0.1 M Glucose, prepared in $1 \mathrm{mM}$ HEPES (pH 7.4), for observation. A typical observation experiment, using an inverted microscope was made in an observation chamber by mixing $30 \mu \mathrm{L}$ of the GUVs solution with $100 \mu \mathrm{L}$ of a $0.1 \mathrm{M}$ glucose solution. This created a sugar asymmetry between the interior and the exterior of the vesicles. The slight densities difference between the inner and outer solutions drive the vesicles to the bottom slide where they can easily be observed and in addition, the refractive index difference between sucrose and glucose solutions provides a better contrast when observing the vesicles with phase contrast microscopy. Typical protein concentrations for all the experiments were taken $20 \mu \mathrm{M}$.

Instrumentation. The high resolution transmission electron microscopy (HR-TEM) image was obtained using JEOL-JEM-2100F transmission electron microscope. Sample of citrate stabilized gold nanoparticle (ctGNP) was drop casted on carbon coated copper grid and analysed. Optical absorption spectra were recorded by UV-vis spectrophotometer (Shimadzu, UV-2450) using a cuvette of $1 \mathrm{~cm}$ path length. The fluorescence emission spectra of all samples were obtained with a PTI fluorescence spectrometer (Photon Technology International). The slits for excitation and emission were set at $5 \mathrm{~nm}$. All measurements were done repeatedly and reproducible results were obtained.

Far-UV CD spectra of KMP-11, MPT63 and $\alpha$-synuclein ( $\alpha$-syn) were recorded using a JASCO J720 spectropolarimeter (Japan Spectroscopic Ltd.). Far-UV CD measurements (between 190 and $240 \mathrm{~nm}$ ) were performed using a cuvette of $1 \mathrm{~mm}$ path length. A protein concentration of 10 $\mu \mathrm{M}$ was used for $\mathrm{CD}$ measurements. The scan speed was $50 \mathrm{~nm} \mathrm{~min}^{-1}$ with a response time of $2 \mathrm{~s}$. The bandwidth was taken as $1 \mathrm{~nm}$. Three CD spectra were recorded in the continuous mode and averaged.

FT-IR spectra of the samples were recorded a Bruker tensor 27 FT-IR spectrometer. The buffer baseline was subtracted before each FT-IR spectrum was recorded. The deconvolution of raw FT-IR spectra in the amide I region (from 1700 to $1600 \mathrm{~cm}^{-1}$ ) was done. The assignment of peaks was done using previously reported spectral components associated with the secondary structures. ${ }^{7,8}$ 
Zetasizer Nano ZS (Malvern Instruments Ltd.) was used to measure zeta potential and size distribution at room temperature $\left(25^{\circ} \mathrm{C}\right)$. The backscattered light at $173^{\circ}$ was collected by the photodiode detector. The detected scattered light is sent to the signal processing correlator. Each zeta potential measurement of 100 runs and size measurement of 10-100 runs has been performed. The sample was allowed to equilibrate for $60 \mathrm{~s}$ prior to analysis. All data were collected and analyzed using Malvern Zetasizer 7.11 software.

AFM images were characterized using a Pico Plus 5500 AFM system (Agilent Technologies) in AAC mode. Images were processed using PicoView software (Agilent Technologies).

Binding of proteins with ctGNP. Fluorescence quenching of tryptophan and tyrosine residues was measured with increasing concentrations of ctGNP. Fluorescence intensities were plotted against the concentration of ctGNP and data were fitted using sigmoidal Hill model following the equation:

$F=F_{0}+\frac{\left(F_{e}-F_{0}\right) x^{n}}{\left(x^{n}+K^{n}\right)}$

where, $F$ and $F_{0}$ refer to the intrinsic tryptophan/tyrosine fluorescence intensities of in the presence and absence of ctGNP, respectively. $F_{e}$ denotes the minimum intensity in the presence of a higher concentration of protein, and $K$ is the equilibrium dissociation coefficient of the protein-ctGNP conjugates. $n$ is the Hill coefficient, which measures the cooperativity of binding, and $x$ is the concentration of the ctGNP. For KMP-11 and $\alpha$-syn, we have used equation (1) because in these cases, protein-ctGNP binding occurred through single state binding process. But for the case of MPT63 the binding occurred in two state binding manner. Therefore data were fitted using two state binding model as follows:

$F=F_{0}+\frac{\left(F_{1}-F_{0}\right) x^{n 1}}{\left(x^{n 1}+K 1^{n 1}\right)}+F_{1}+\frac{\left(F_{2}-F_{1}\right) x^{n 2}}{\left(x^{n 2}+K 2^{n 2}\right)}$

where, $F_{0}, F_{1}, F_{2}$ are tryptophan fluorescence intensities in absence and presence of two different concentrations of ctGNPs respectively. $n 1$ and $n 2$ are the cooperativity and $K 1$ and $K 2$ are the equilibrium dissociation constants and $x$ is the concentration of ctGNP.

Lifetime measurements. The fluorescence lifetime of the tryptophan residue does not change by static quenching; hence, time-resolved fluorescence experiments can unambiguously determine 
the dynamic quenching constant. Fluorescence lifetimes were measured using time-correlated single-photon-counting (TCSPC) equipment (Fluorocube Fluorescence Lifetime System by Horiba JovinYvon) using a picosecond pulsed diode laser with excitation at $\lambda_{\mathrm{ex}}=295 \mathrm{~nm}$. The total intensity decay curves, $I(t)$, were fitted to a biexponential function,

$I(t)=A_{1} e^{-\left(\frac{t}{T 1}\right)}+A_{2} e^{-\left(\frac{t}{T 2}\right)}$

where $A_{i}$ and $T_{i}$ denote the amplitude and lifetime of the $\mathrm{i}^{\text {th }}$ species. Fitting was done by an iterative procedure using the DAS 6.2 data analysis software supplied by IBH. Reduced and weighted residuals served as parameters for ensuring goodness of fit. The average lifetime of the tryptophan residue has been calculated using the following equation:

$T_{a v g}=\left(A_{1} T_{1}^{2}+A_{2} T_{2}^{2}\right)$

The average lifetimes in the absence and presence of an acrylamide quencher have been denoted as $T_{\text {avg }}^{0}$ and $T_{\text {avg }}$, respectively.

Binding Assay Using Fluorescence Spectroscopy. A fluorometric assay was done for studying the binding of MPT63, KMP-11 and $\alpha$-syn with LUVs composed of DOPC-DOPG mixtures. All samples were prepared in $20 \mathrm{mM}$ sodium phosphate buffer at $\mathrm{pH}$ 7.4. A set was prepared using 1 $\mathrm{mM}$ concentration of uniformly synthesized lipid vesicles. In each sample vial, $0.5 \mathrm{wt} \%$ of membrane-specific DiIC-18 dye was added. The samples were kept at $37{ }^{\circ} \mathrm{C}$ for overnight incubation. Then the required amount of protein was added into the vials by maintaining the lipid/protein molar ratio between 1:0 and 50:1. The samples were then incubated at room temperature $\left(25^{\circ} \mathrm{C}\right)$ for $2 \mathrm{~h}$. The steady-state fluorescence emission spectra of the dye were recorded at an excitation wavelength of $600 \mathrm{~nm}$. The peak intensity values at $670 \mathrm{~nm}$ for DOPCDOPG mixture were plotted with protein concentration. The data have been fitted using the Hill equation (1) where, $F$ and $F_{0}$ refer to the fluorescence intensities of DiIC-18 in the presence and absence of protein, respectively. $F_{e}$ denotes the minimum intensity in the presence of a higher concentration of protein, and $K$ is the equilibrium dissociation coefficient of the lipid-protein complex. $n$ is the Hill coefficient, which measures the cooperativity of binding, and $x$ is the concentration of the protein. ${ }^{9}$ 
Acrylamide Quenching Data Analysis. Assuming $F$ and $F_{0}$ are the tryptophan fluorescence intensity of the proteins in the presence and absence of acrylamide concentration, $[Q]$, the SternVolmer equation can be represented as follows:

$$
\frac{F_{0}}{F}=1+K_{s v}[Q]
$$

$K_{s v}$ is the Stern-Volmer constant, which can be determined from the slope of the linear plot of $F_{0} / F$ versus acrylamide concentration, $[Q] \cdot{ }^{10}$

\section{Unfolding transition of WT-MPT63 at pH 7.5 and 5, W26F, WT MPT63-ctGNP at pH 7.5}

Unfolding of different protein species was performed using Guanidium hydrochloride $(\mathrm{GdmCl})$ by monitoring the quenching of tryptophan fluorescence. Typical protein concentration of $5 \mu \mathrm{M}$ was used for unfolding experiments. Experimental data were fit using the two-state transition model as follows (Eqn 6):

$\boldsymbol{y}=\left\{\left(y_{n}+\boldsymbol{m}_{\boldsymbol{n}} * \boldsymbol{x}\right)+\left(\boldsymbol{y}_{\boldsymbol{d}}+\boldsymbol{m}_{\boldsymbol{d}} * \boldsymbol{x}\right) * \mathrm{e}^{\left[-\left(\Delta G^{0}+m *\left(\frac{x}{0.582630}\right)\right]\right\}} /\left\{1+\boldsymbol{e}^{\left[-\left(\Delta G^{0}+m *\left(\frac{x}{0.582630}\right)\right]\right\}}\right.\right.$

where, $y$ denotes the observed fluorescence intensity, $y_{n}$ and $y_{d}$ refers to fluorescence signals at native and unfolded conditions respectively. $\Delta G^{0}$ stands for free energy of unfolding transition, $m$ is the cooperativity and $x$ denotes the concentration of $\mathrm{GdmCl}$. All data analysis and fitting were carried out using OriginPro 8.5.

Assay for permeabilization of lipid vesicles. The ability of proteins and protein-ctGNP conjugates to cause release of entrapped vesicle contents for LUVs composed of PC-PG was checked by monitoring the increase in fluorescence intensity of calcein, encapsulated in vesicles at high self-quenching concentrations $(10 \mathrm{mM})$, upon addition of proteins. ${ }^{11}$ Calcein-loaded liposomes were separated from non-encapsulated (free) calcein by gel filtration on a Sephadex G-75 column (Sigma) using an elution buffer of $10 \mathrm{mM} \mathrm{NaP}(\mathrm{pH}$ 7.5). The excitation wavelength was $490 \mathrm{~nm}$ and emission was set at $520 \mathrm{~nm}$. The high concentration $(10 \mathrm{mM})$ of the entrapped calcein led to self-quenching of its fluorescence resulting in low fluorescence intensity of the vesicles $\left(I_{B}\right)$. Release of calcein caused by addition of proteins and protein-ctGNP conjugates led to the dilution of the dye into the medium, which could therefore be monitored by an enhancement of fluorescence intensity $\left(I_{F}\right)$. This enhancement of fluorescence is a measure of the extent of vesicle permeabilization. The experiments were normalized relative to the total 
fluorescence intensity $\left(I_{T}\right)$ corresponding to the total release of calcein after complete disruption of all the vesicles by addition of Triton X-100 (2\% v/v):

$$
\% \text { Release }=100 \frac{\left(I_{F}-I_{B}\right)}{\left(I_{T}-I_{B}\right)}
$$

where, $I_{B}$ is the background (self-quenched) intensity of calcein encapsulated in vesicles, $I_{F}$ represents the enhanced fluorescence intensity resulting from the dilution of dye in the medium caused by protein-induced release of entrapped calcein. $I_{T}$ is the total fluorescence intensity after complete permeabilization is achieved upon addition of Triton X-100.

Labeling of the Protein with Alexa488Maleimide. Since MPT63 protein lacks cysteine G20C mutant of MPT63 was used for these experiments. The protein was labelled with Alexa488Maleimide (Alexa488) using a previously published procedure. Briefly, Alexa488 dissolved in DMSO was slowly added to $2 \mathrm{mg} \mathrm{mL}^{-1}$ solution of the protein under constant stirring. The molar ratio between the dye and protein was maintained at 10:1. The reaction mixture was incubated at $4{ }^{\circ} \mathrm{C}$ for $5 \mathrm{~h}$, with shaking after every $30 \mathrm{~min}$. The labelling reaction was then stopped by adding excess $\beta$-mercaptoethanol. Excess free dye from the reaction mixture was removed by extensive dialysis followed by column chromatography using a Sephadex G20 column which was pre-equilibrated with $20 \mathrm{mM}$ sodium phosphate buffer ( $\mathrm{pH} 7.5) .{ }^{12}$

Fluorescence Correlation Spectroscopy (FCS) Experiments and Data Analysis. FCS experiments were carried out using a dual channel ISS Alba V system equipped with a $60 \mathrm{X}$ water-immersion objective (NA 1.2). Samples were excited with an argon laser at $488 \mathrm{~nm}$. All protein data were normalized using the $\tau_{D}$ value obtained with the free dye (Alexa488) which was measured under identical conditions. For a single-component system, diffusion time $\left(\tau_{D}\right)$ of a fluorophore and the average number of particles $(N)$ in the observation volume can be calculated by fitting the correlation function $[G(\tau)]$ to Eq. 8:

$$
G(\tau)=1+\left(\frac{1}{N\left(1+\frac{\tau}{\tau D}\right)}\right) \frac{1}{\sqrt{1+S^{2} \frac{\tau}{\tau_{D}}}}
$$

where, $S$ is the structure parameter, which is the depth-to-diameter ratio. The characteristic diffusion coefficient $(D)$ of the molecule can be calculated from $\tau_{D}$ using Eq. 9: 


$$
\tau D=\frac{\omega^{2}}{4 D}
$$

where, $\omega$ is the radius of the observation volume, which can be obtained by measuring the $\tau_{D}$ of a fluorophore with known $D$ value. The value of hydrodynamic radius $\left(r_{H}\right)$ of a labelled molecule can be calculated from $D$ using the Stokes-Einstein equation [Eq. 10]:

$$
D=\frac{k T}{6 \pi \eta \eta_{H}}
$$

where, $k$ is the Boltzmann constant, $T$ is the temperature and $\eta$ corresponds to the viscosity of the solution. ${ }^{13}$

Flow cytometry. For FACS analyses overnight incubated M $\phi$ s (RAW 264.7) were treated with $20 \mu \mathrm{M}$ of WT MPT63 and its different variants like MPT63 at pH 5, W26F, WT MPT63-ctGNP and low $\mathrm{pH}$ control as mentioned for $24 \mathrm{hr}$ after which the cells were washed with 1X PBS and then re-suspended in $500 \mu \mathrm{l}$ of $1 \mathrm{X}$ binding buffer (abcam). The cells were then treated with $5 \mu 1$ of Annexin V-FITC and $5 \mu \mathrm{l}$ of PI followed by incubation at room temperature for 5 mins as per manufacturer's instruction (abcam). Cells were then analysed in flow cytometer (BD FACS Verse).

Trypan blue assay. Overnight incubated cells (RAW 264.7) were treated with $20 \mu \mathrm{M}$ of MPT63 for $24 \mathrm{hr}$. After incubation cells were washed with 1X PBS and then treated with $0.4 \%$ trypan blue dye (Sigma-Aldrich) for approximately $3 \mathrm{~min}$ after which the cells were subjected to microscopic examination under 40X magnification. ${ }^{14}$ 


\section{Conformational switch in WT MPT63 with varying input signals: Ligand binding, $p H$ and site}

specific mutation:

Ligand binding, $\mathrm{pH}$ effect and site specific mutation is the most well-known variables that modulate protein structure-function relationship. We employed small sized citrate capped gold nanoparticles (ctGNPs) as ligand since in our recent work, we already reported GNP induced conformational transition in MPT63. ${ }^{1}$

Synthesized ctGNP was characterized by TEM and DLS experiments (Figure S1). Protein adsorption on GNP surface was first affirmed by a significant red shift of the SPR band from $\sim 520 \mathrm{~nm}$ to $\sim 533 \mathrm{~nm}$ and these shifts in absorbance maxima are comparable for all three proteins (Figure S2a-c). Surprisingly, concentration dependent SPR profile of WT MPT63 was found to be different from KMP-11 and $\alpha$-syn. In Figure S2a, we observed "Rise and Dip" event in SPR band intensity for WT MPT63 which was absent for other two proteins (Figure S2b-c). This observation suggests the presence of protein's conformational influences on the adsorption profile of proteins on GNP surface. Tryptophan (for MPT63 and KMP-11, it is to be noted that KMP-11 does not have any tryptophan in its native form and therefore one of its structurally similar mutant namely Y5W was used) and tyrosine (for $\alpha$-syn; $\alpha$-syn gives significant fluorescence intensity due to presence of a number of tyrosine residues) fluorescence were probed to monitor the impact of structural contribution on the protein adsorption. Interestingly, fluorescence quenching profiles of WT MPT63 with addition of ctGNP is different from $\alpha$-syn and KMP-11(Figure S2d-f). ctGNP induced intrinsic fluorescence quenching may be initiated by static or dynamic mechanism. Linear behaviors of Stern-Volmer plot were observed for both KMP-11 and $\alpha$-syn whereas nonlinear nature of the curve was registered for WT MPT63 (Figure S2g-h) suggesting the quenching mechanism of WT MPT63 is quite different from that of KMP11 as well as $\alpha$-syn.

Steady state tryptophan fluorescence quenching of WT MPT63 with increasing concentration of ctGNP was fitted using two state sigmoidal binding equation (Eqn 2, Figure S3a). Fluorescence lifetime measurements suggested that with addition of ctGNP, no appreciable changes in $\tau_{\text {avg }}$ was observed for KMP-11 and $\alpha$-syn (Figure S3b-c). On the contrary, significant drop in fluorescence lifetime was observed for WT MPT63 (Figure S3d-e).These data reflected notable existence of both static and dynamic components in the quenching event of WT MPT63 whereas for other two proteins, only static component (ground state quenching) is responsible for quenching. In 
addition, lifetime data further inferred that WT MPT63 showed the lifetime decay curve which is quite closer to single exponential in nature in the absence of ctGNP but gradual shifting of decay pattern from single to double exponential along with reduction in average lifetime was addressed with addition of ctGNP (Figure S3d-e). Although the lifetime decay of WT MPT63 was fitted satisfactorily to a sum of two component but the amplitude of short life time component is very small $(2 \%)$ in comparison to the large component (98\%) but addition of ctGNP gradually increased the short component with concomitant decrease in large component indicating the shift from nearly single exponential to bi-exponential character (Figure S3d-e, Table S1). According to the above results, there may occur some local opening up or conformational changes of WT MPT63 protein as a result of the adsorption on ctGNP surface. Stern-Volmer constants $\left(K_{s v}\right.$ values from acryl amide quenching) were found to get decreased for KMP-11 and $\alpha$-syn upon adsorption on ctGNP surfaces suggesting the reduction in tryptophan and tyrosine exposure due to adsorption (Figure S10, Table S5). In contrast, $K_{s v}$ value significantly increased for WT MPT63 while it is adsorbed on ctGNP surface (Table S5).

Structural fluctuation due to ctGNP binding was monitored by CD suggesting insignificant structural change of KMP-11 and $\alpha$-syn (Figure S4a-b) whereas noticeable increase in helical content along with the unfolding was observed for WT MPT63 (Figure S4c). Figure S4c showed clearly the reduction of beta sheet extent along with the increase of alpha helical content in WTMPT63 with increasing concentration of ctGNP. We found appreciable rise of the vibrational frequency at $1650 \mathrm{~cm}^{-1}$ (designating the alpha helix) with concomitant drop of $1638 \mathrm{~cm}^{-1}$ (designating beta sheet conformation) (Figure 1c). Hence, both CD and FTIR data signified beta sheet to alpha helix switch in WT MPT63 due to adsorption on ctGNP surfaces, while insignificant structural changes were observed for KMP-11 and $\alpha$-syn.

Another two most important modulating factors inducing the conformational switch in a protein are solution $\mathrm{pH}$ and mutational effect. We have generated the conformational switch in MPT63 by reducing the solution $\mathrm{pH}$ from 7.5 to 1.5 . A gradual increase in ellipticity at $222 \mathrm{~nm}$ indicated the gain of alpha helical character with reducing the solution $\mathrm{pH}$ (Figure S4e). CD data was also cross-confirmed by the FT-IR measurement. Besides, small hydrophobic exchange in the $26^{\text {th }}$ position of chameleon sequence stretch in WT MPT63 through site directed mutagenesis generated W26F mutant which also showed conformational switch due to mutational effect. ${ }^{1}$ The existence of alpha helical secondary organization in W26F was already characterized by CD as 
well as FT-IR spectroscopy in our previous reports. ${ }^{1}$ Again we have monitored the adsorption profile of W26F mutant on ctGNP surface. W26F showed adsorption profile unlike WT MPT63 as evident by negligible quenching of SPR band intensity (Figure S5a); static quenching of tryptophan fluorescence (Figure S5b), insignificant change in average lifetime (Figure S5c) and bi-exponential decay nature of the lifetime curve. The lifetime decay curve of W26F showed relatively comparable amplitudes of both short and large lifetime components in both ctGNP bound and unbound conditions (Table S2) which further inferred that W26F behaved like WT MPT63-ctGNP conjugates without any conformational loss. 
Table S1. Life time data of WT MPT63 in the presence of increasing concentration of ctGNP

\begin{tabular}{ccccccc}
$\begin{array}{c}\text { ctGNP } \\
\text { conc. }(\boldsymbol{\mu M})\end{array}$ & $\boldsymbol{\tau}_{\mathbf{1}}(\mathbf{n s})$ & $\boldsymbol{\tau}_{\mathbf{2}}(\mathbf{n s})$ & $\mathbf{A}_{\mathbf{1}}$ & $\mathbf{A}_{\mathbf{2}}$ & $\boldsymbol{\tau}_{\text {avg }}(\mathbf{n s})$ & $\chi^{\mathbf{2}}$ \\
\hline $\mathbf{0}$ & 0.27 & 4.17 & 0.02 & 0.98 & 4.15 & 1.09 \\
$\mathbf{2}$ & 2.15 & 4.16 & 0.03 & 0.97 & 4.12 & 1.11 \\
$\mathbf{4}$ & 1.99 & 4.16 & 0.05 & 0.95 & 4.07 & 1.07 \\
$\mathbf{6}$ & 1.37 & 4.15 & 0.08 & 0.92 & 4.06 & 1.16 \\
$\mathbf{8}$ & 1.62 & 4.09 & 0.11 & 0.89 & 4.01 & 1.20 \\
$\mathbf{1 0}$ & 1.31 & 4.04 & 0.09 & 0.91 & 3.80 & 1.01 \\
$\mathbf{1 2}$ & 1.26 & 4.03 & 0.09 & 0.91 & 3.94 & 1.05 \\
$\mathbf{1 5}$ & 1.74 & 3.92 & 0.15 & 0.85 & 3.75 & 1.14 \\
$\mathbf{2 0}$ & 1.83 & 3.93 & 0.22 & 0.78 & 3.69 & 1.29 \\
$\mathbf{2 5}$ & 1.65 & 3.87 & 0.18 & 0.82 & 3.67 & 1.02 \\
\hline
\end{tabular}


Table S2. Life time data of W26F in the presence of increasing concentration of ctGNP

\begin{tabular}{ccccccc}
$\begin{array}{c}\text { ctGNP } \\
\text { conc. }(\boldsymbol{\mu M})\end{array}$ & $\boldsymbol{\tau}_{\mathbf{1}}(\mathbf{n s})$ & $\boldsymbol{\tau}_{\mathbf{2}}(\mathbf{n s})$ & $\mathbf{A}_{\mathbf{1}}$ & $\mathbf{A}_{\mathbf{2}}$ & $\boldsymbol{\tau}_{\text {avg }}(\mathbf{n s})$ & $\chi^{\mathbf{2}}$ \\
\hline $\mathbf{0}$ & 1.8 & 3.92 & 0.30 & 0.69 & 3.57 & 1.11 \\
$\mathbf{2}$ & 1.75 & 3.94 & 0.29 & 0.70 & 3.59 & 1.14 \\
$\mathbf{4}$ & 1.73 & 3.91 & 0.27 & 0.73 & 3.61 & 1.01 \\
$\mathbf{6}$ & 1.75 & 3.87 & 0.26 & 0.74 & 3.58 & 1.05 \\
$\mathbf{8}$ & 1.72 & 3.86 & 0.25 & 0.75 & 3.58 & 1.17 \\
$\mathbf{1 0}$ & 1.75 & 3.95 & 0.31 & 0.69 & 3.59 & 1.19 \\
$\mathbf{1 5}$ & 1.68 & 3.88 & 0.26 & 0.74 & 3.59 & 1.10 \\
$\mathbf{2 0}$ & 1.61 & 3.86 & 0.25 & 0.75 & 3.58 & 1.08 \\
\hline
\end{tabular}


Table S3. Change in Free energy of transfer as obtained from the OPM computational analysis

\begin{tabular}{cc}
\hline Protein & $\Delta \mathbf{G}$ transfer $\left(\right.$ kcal mol $\left.^{-1}\right)$ \\
\hline$\alpha-$ Syn & -8.4 \\
KMP-11 & -4.8 \\
WT MPT63 & -2.4 \\
\hline
\end{tabular}


Table S4. Quantitative estimation of binding constants $\left(\mathrm{K}_{\mathrm{a}}\right)$, and cooperativity (n) of different protein-membrane systems

\begin{tabular}{|ccc|}
\hline Variations & $\mathbf{n}$ & $\mathbf{K}_{\mathbf{a}}\left(\mathbf{M}^{-\mathbf{1}}\right)$ \\
\hline WT MPT63 $(\mathbf{p H}$ 7.5) + PCPG & $1.68 \pm 0.08$ & $(9.50 \pm 0.35) \times 10^{3}$ \\
\hline W26F + PCPG & $2.17 \pm 0.10$ & $(3.29 \pm 0.67) \times 10^{6}$ \\
\hline WT MPT63-ctGNP + PCPG & $1.72 \pm 0.08$ & $(3.45 \pm 0.58) \times 10^{6}$ \\
\hline WT MPT63 $(\mathbf{p H}$ 5) + PCPG & $1.76 \pm 0.08$ & $(2.46 \pm 0.43) \times 10^{5}$ \\
\hline $\boldsymbol{\alpha}$-syn + PCPG & $0.87 \pm 0.04$ & $(9.80 \pm 0.28) \times 10^{5}$ \\
\hline KMP11 + PCPG & $0.51 \pm 0.02$ & $(1.44 \pm 0.72) \times 10^{5}$ \\
\hline
\end{tabular}


Table S5. Stern-Volmer constants $\left(\mathrm{K}_{\mathrm{sv}}, \mathrm{M}^{-1}\right)$ obtained from acrylamide quenching studies for different proteins in its membrane bound and unbound conditions

\begin{tabular}{cc|} 
Variations & $\mathbf{K}_{\mathbf{s v}}$ \\
\hline WT MPT63 (pH 7.5) & $4.70 \pm 0.13$ \\
\hline WT MPT63 (pH 7.5) + PCPG & $4.17 \pm 0.21$ \\
WT MPT63-ctGNP & $5.43 \pm 0.32$ \\
\hline WT MPT63-ctGNP + PCPG & $3.50 \pm 0.42$ \\
W26F & $5.85 \pm 0.16$ \\
W26F + PCPG & $4.48 \pm 0.20$ \\
WT MPT63 (pH 5) & $6.43 \pm 0.18$ \\
\hline WT MPT63 (pH 5) + PCPG & $4.83 \pm 0.14$ \\
$\boldsymbol{\alpha}-$-syn & $10.22 \pm 0.19$ \\
$\boldsymbol{\alpha}-$-syn + PCPG & $6.87 \pm 0.42$ \\
$\boldsymbol{\alpha}-$-syn ctGNP & $8.76 \pm 0.38$ \\
$\boldsymbol{\alpha}-$-syn ctGNP + PCPG & $6.63 \pm 0.34$ \\
KMP11 & $3.69 \pm 0.22$ \\
KMP11 + PCPG & $1.70 \pm 0.25$ \\
KMP11 ctGNP & $2.44 \pm 0.37$ \\
\hline KMP11 ctGNP + PCPG & $1.31 \pm 0.30$ \\
\hline
\end{tabular}


Table S6. Sequence alignment with WT MPT63 with the known pore forming toxins

\begin{tabular}{|c|c|}
\hline Name of the protein (PDB ID) & Percent identity \\
\hline Aerolysin (5JZH) & 24.6 \\
\hline Colicin N (1A87) & 17.5 \\
\hline Colicin 1A (1CII) & 21.9 \\
\hline Colicin A (1COL) & 21.4 \\
\hline Colicin E1 (2I88) & 24.3 \\
\hline Colicin M (2XMX) & 23.1 \\
\hline Cytolysin A (2WCD) & 24.6 \\
\hline Equinatoxin (1IAZ) & 20.7 \\
\hline Hemolysin BL (2NRJ) & 22.3 \\
\hline Hemolysin E (1QOY) & 24.4 \\
\hline Hemolysin (7AHL) & 21.8 \\
\hline Leukocidin (1LKF) & 17.7 \\
\hline Lysenin (3ZXD) & 27.5 \\
\hline Vibrio cholera cytolysin (3O44) & 20.9 \\
\hline ESAT 6 (1WA8) & 14.5 \\
\hline
\end{tabular}



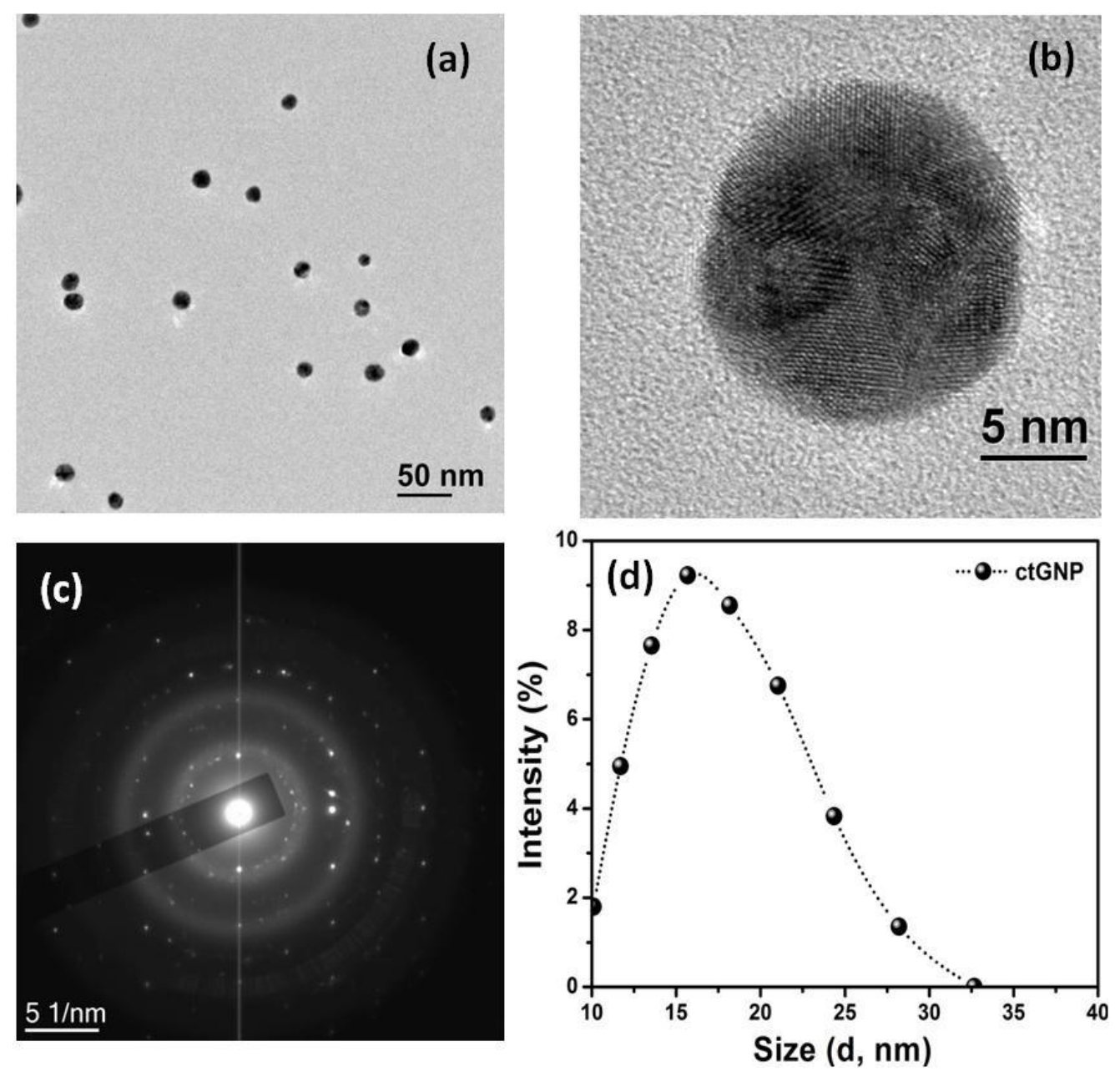

Figure S1. Characterization of ctGNP by TEM and DLS.(a) HR-TEM image of ctGNPs; (b) enlarged image of one ctGNP; (c) SAED pattern and (d) DLS size distribution of ctGNP. 

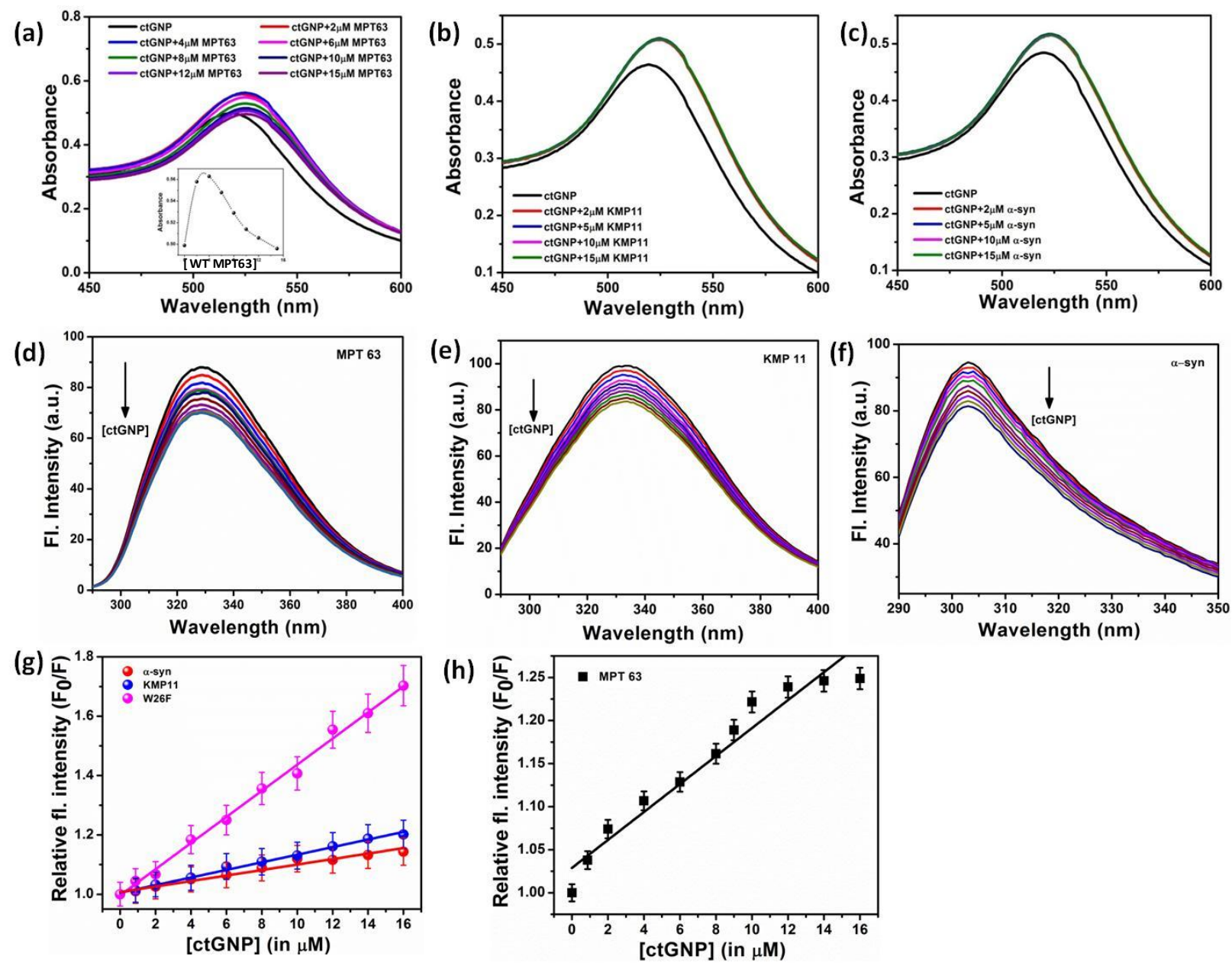

Figure S2. Study of changes in absorbance (ctGNP at $520 \mathrm{~nm}$ ) and protein fluorescence. ctGNP absorbance titration with increasing concentration of (a) WT MPT63, (b) KMP-11 and (c) $\alpha$-syn; Fluorescence titration experiment using (d) WT MPT63, (e) KMP-11 and (f) $\alpha$-syn with increasing ctGNP concentration; (g) Quenching of KMP-11, $\alpha$-syn and W26F as obtained from titration experiment with ctGNP and (h) Quenching of WT MPT63 as obtained from titration experiment with ctGNP. 
(a)

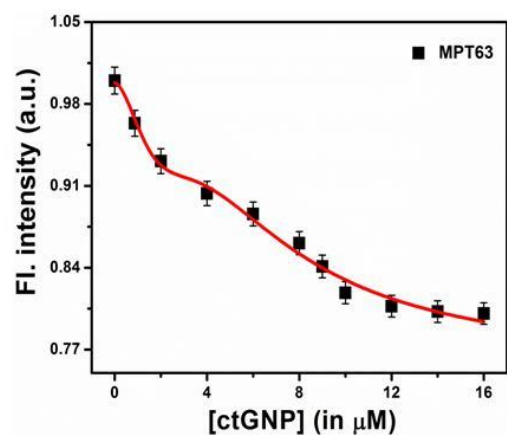

(d)

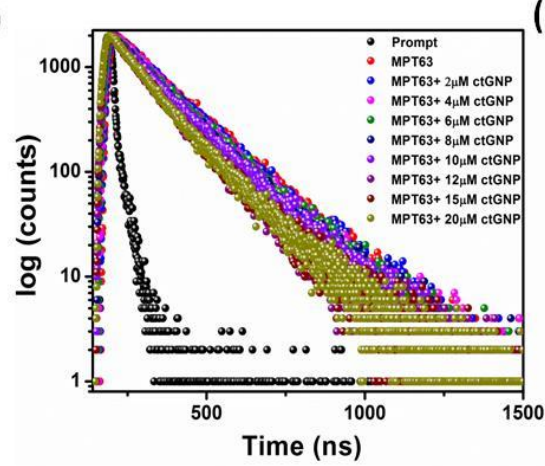

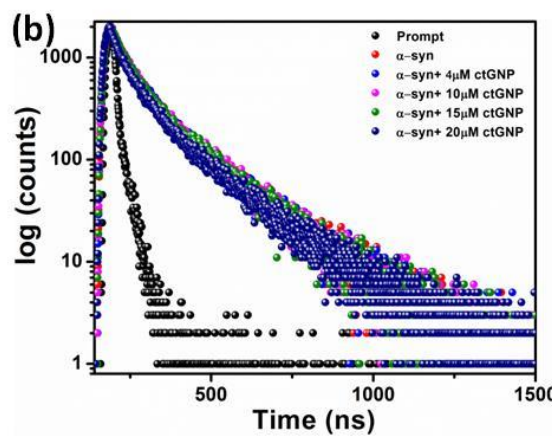

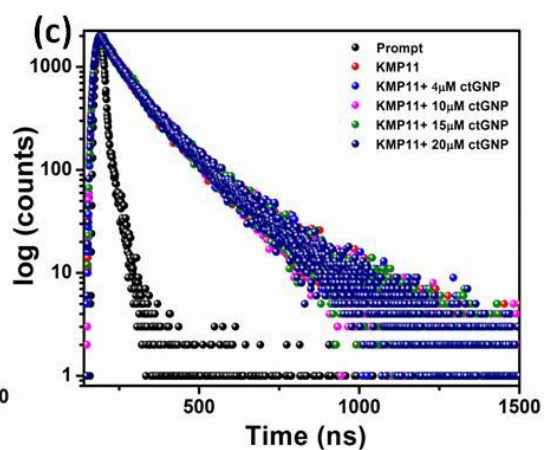

(e)
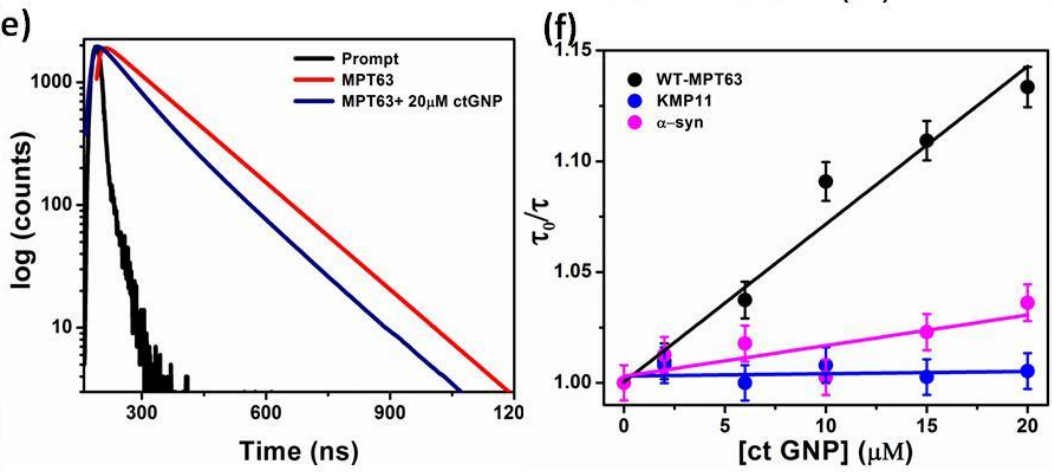

Figure S3. MPT63-ctGNP binding and lifetime measurements. (a) Binding of WT MPT63 with ctGNP fitted using two-state binding model; Time resolved tryptophan and tyrosine fluorescence decay of (b) $\alpha$-syn, (c) KMP-11(Y5W mutant) and (d) WT MPT63 with increasing concentration of ctGNP; (e) fitting curve of lifetime data as obtained for WT MPT63 and WT MPT63-ctGNP conjugate; (f) Stern-Volmer plots of these three proteins obtained from the time resolved data. 

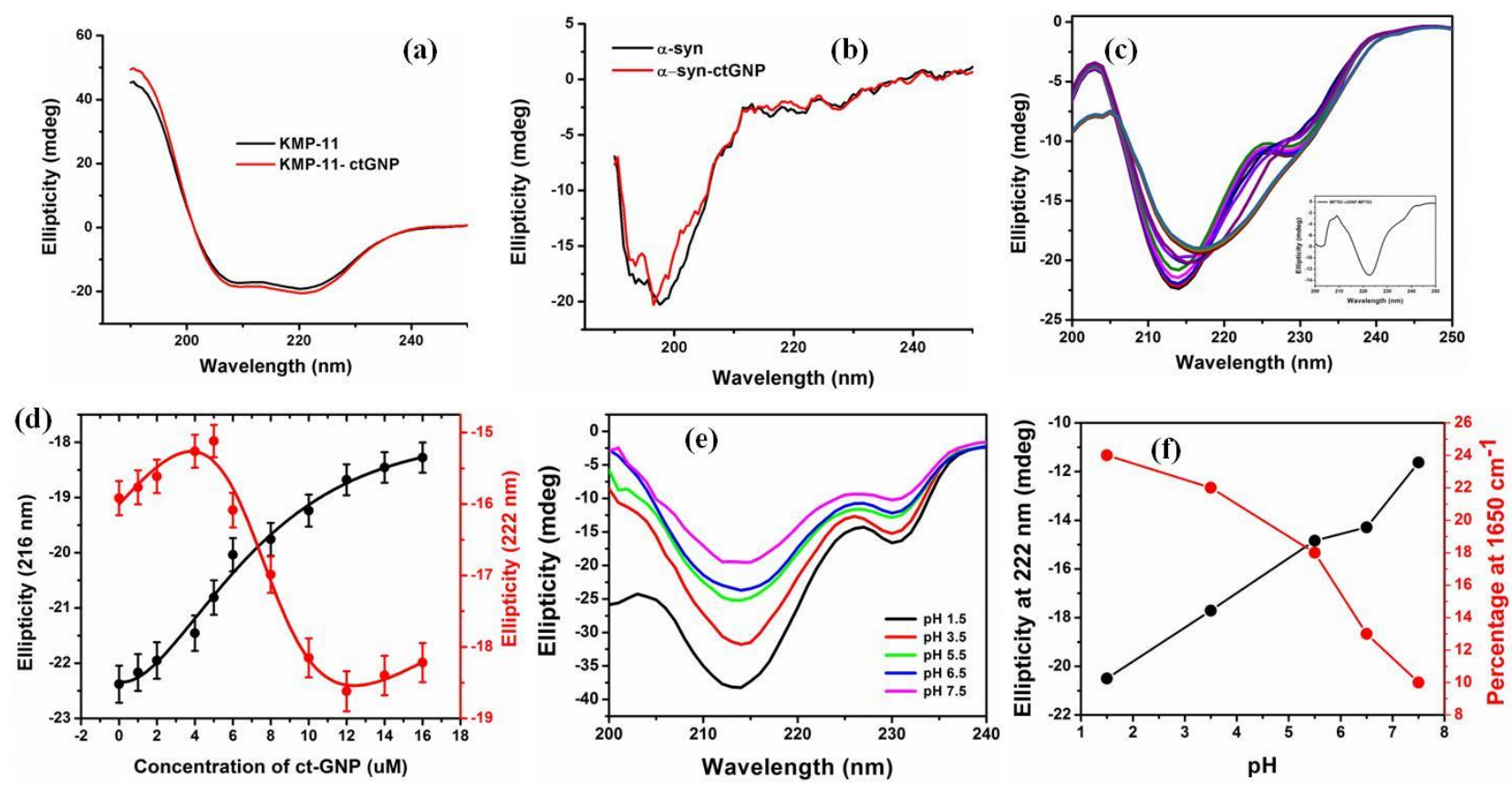

Figure S4. Protein's structural characterization (a) Far-UV CD spectra of KMP-11 and KMP11-ctGNP conjugates; (b) Far-UV CD spectra of $\alpha$-syn and $\alpha$-syn-ctGNP conjugates; (c) Far-UV CD spectra of WT MPT63 with increasing concentrations of ctGNP, inset showing the difference spectra of WT MPT63 and WT MPT63-ctGNP conjugate; (d) Plot showing ellipticity of WT MPT63 at $216 \mathrm{~nm}$ and $222 \mathrm{~nm}$ against concentration of ctGNP; (e) Far-UV CD spectra of WT MPT63 at different solution $\mathrm{pH}$ and (f) Plot showing ellipticity at $222 \mathrm{~nm}$ and percentage of secondary structural component at $1650 \mathrm{~cm}^{-1}$ of WT MPT63 against $\mathrm{pH}$. 

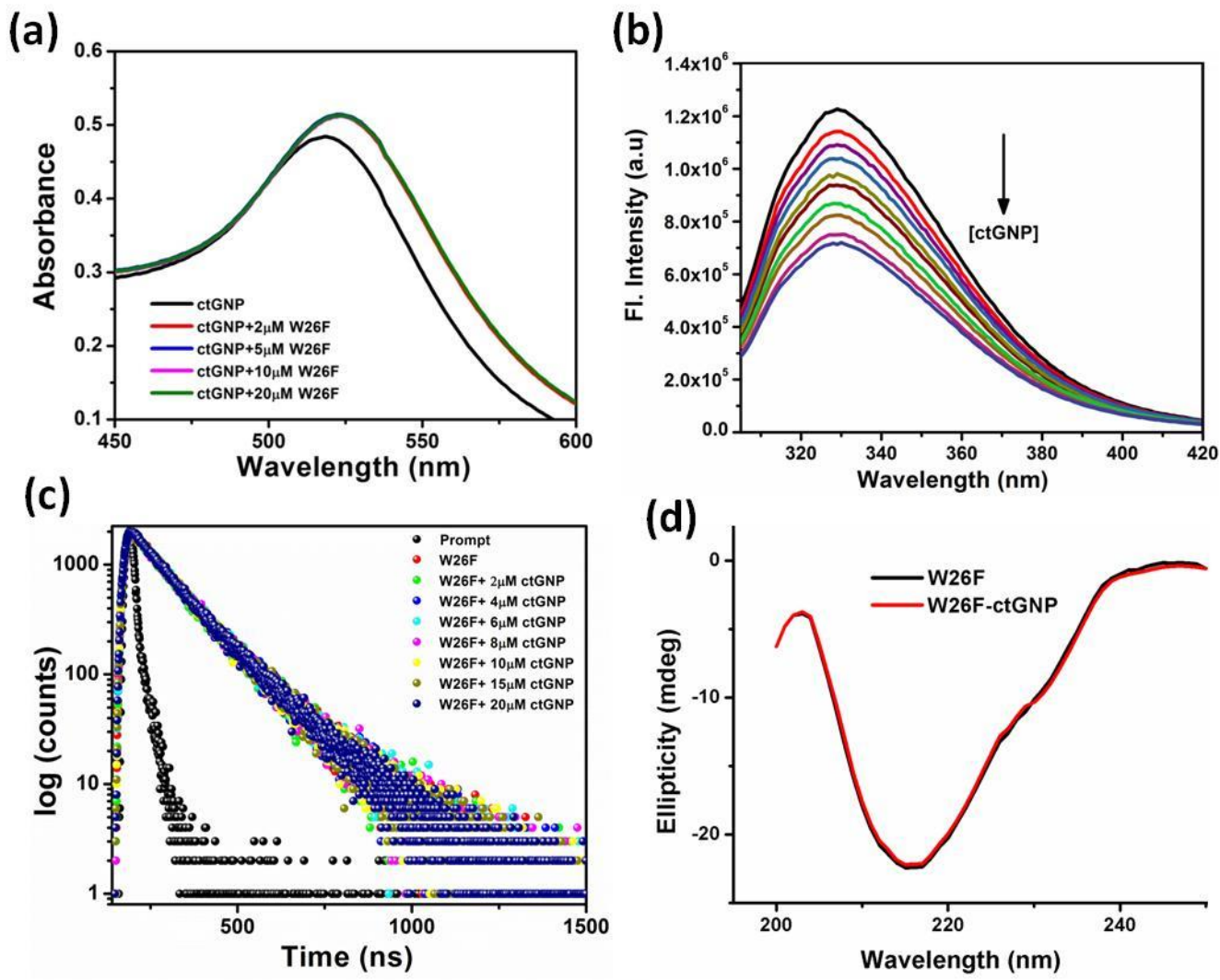

Figure S5: Interaction and structural characterization of W26F mutant in presence of ctGNP (a) UV-vis absorption titration of ctGNP with increasing concentration of W26F; (b) fluorescence titration and (c) time resolved fluorescence decay of W26F with increasing concentrations of ctGNP; (d) Far-UV CD spectra of W26F and W26F-ctGNP conjugates. 


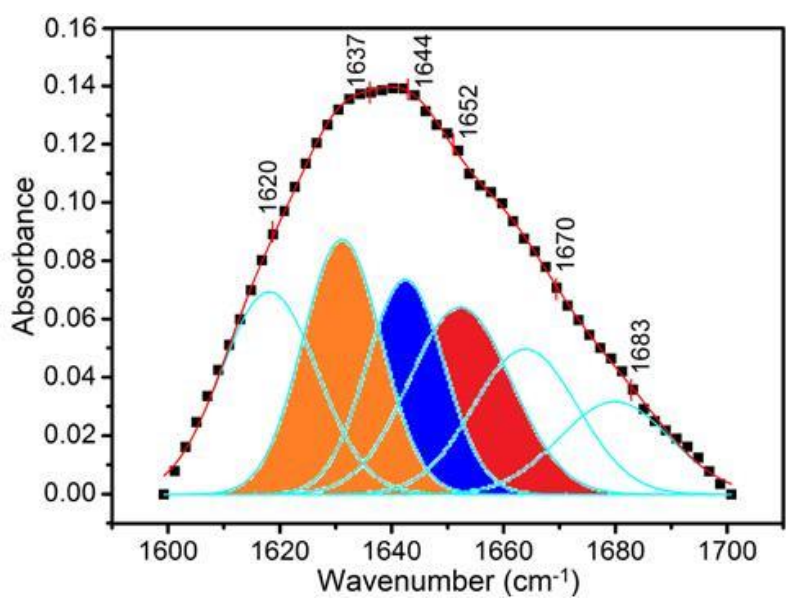

Figure S6: Deconvoluted FT-IR spectral signatures of amide-I region $(\mathrm{C}=\mathrm{O})$ of WT MPT63. Yellow region $\left(1637 \mathrm{~cm}^{-1}\right)$ denotes beta sheet; red region $\left(1652 \mathrm{~cm}^{-1}\right)$ indicates $\alpha$-helix and blue region $\left(1644 \mathrm{~cm}^{-1}\right)$ designates the disorder region of the proteins. Experiment was performed at $\mathrm{pH} 7.5$. 

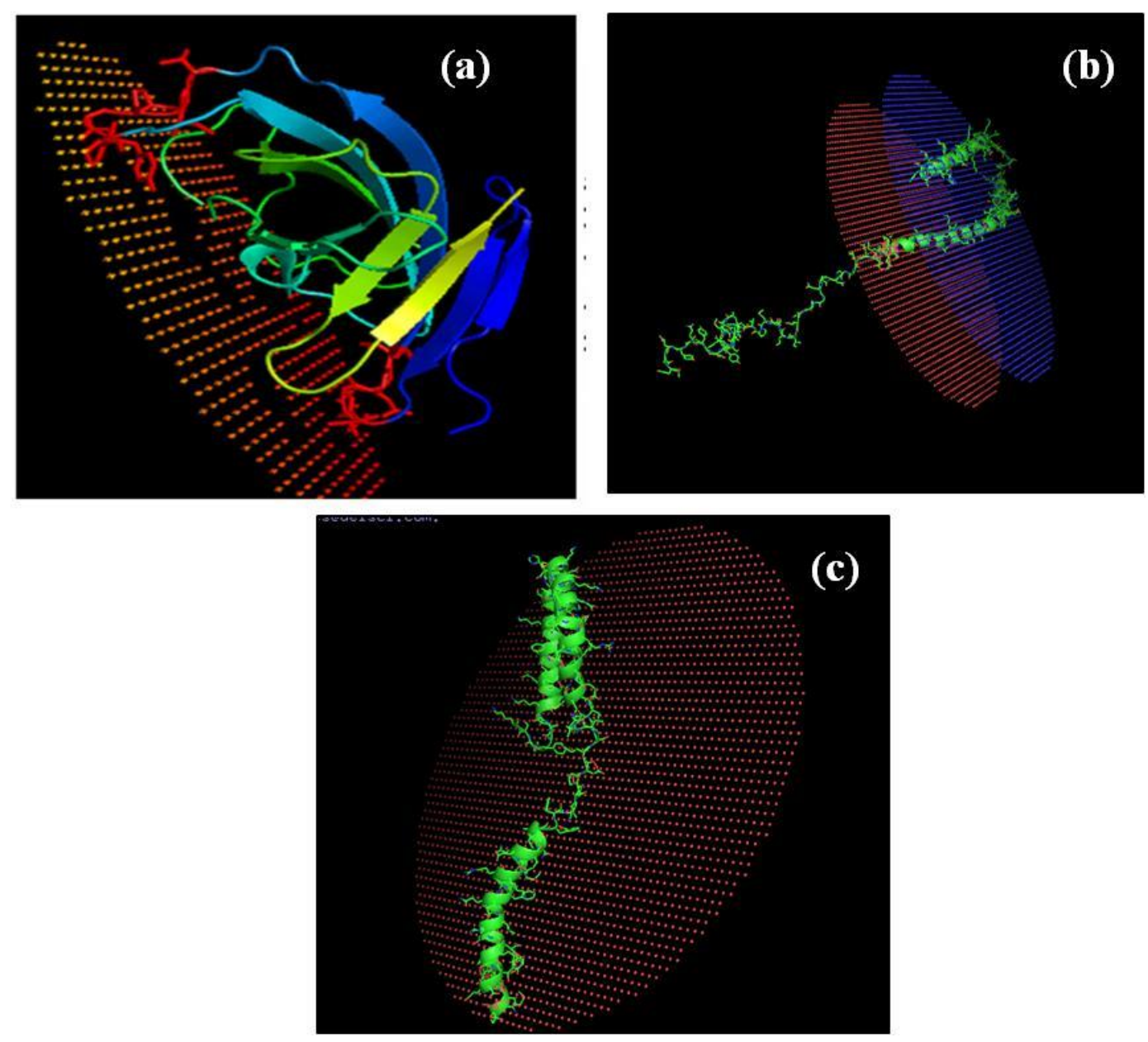

Figure S7. Attachment of proteins with membranes; Orientation of (a) WT MPT63, (b) $\alpha$ syn, and (c) KMP-11 on the phospholipid membrane (obtained using the orientations of proteins in membrane OPM) server. This shows better insertion propensity for KMP-11 and $\alpha$-syn compared to MPT63. 


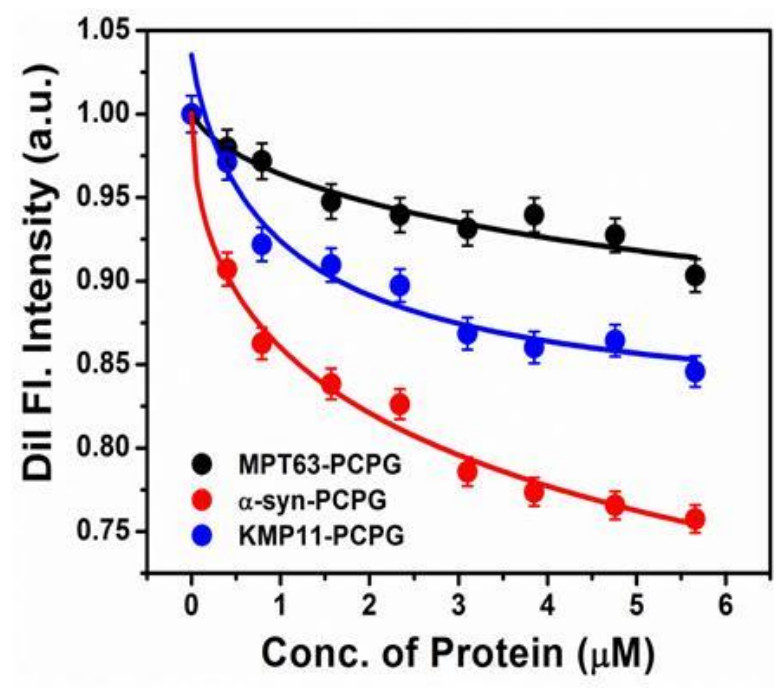

Figure S8: Quenching of fluorescence intensities originating from DiI C-18 in the presence of PCPG LUVs were plotted against the concentration of WT MPT63 at pH 7.5 (black), $\alpha$-syn (red), and KMP-11 (blue). The lines through the data are the fits using the Hill equation. 


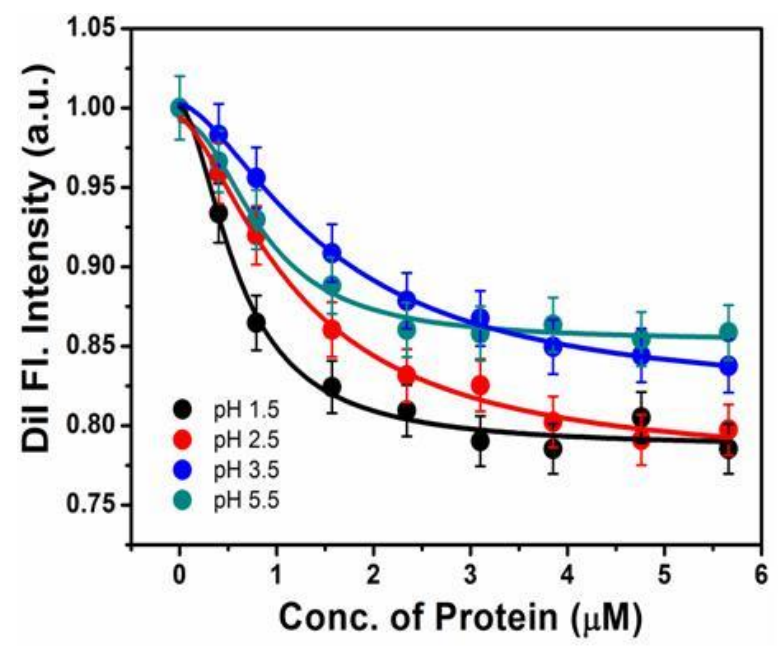

Figure S9: Quenching of fluorescence intensities originating from DiI C-18 in the presence of PCPG LUVs were plotted against the concentration of WT MPT63 at different $\mathrm{pH}$. 
(a)

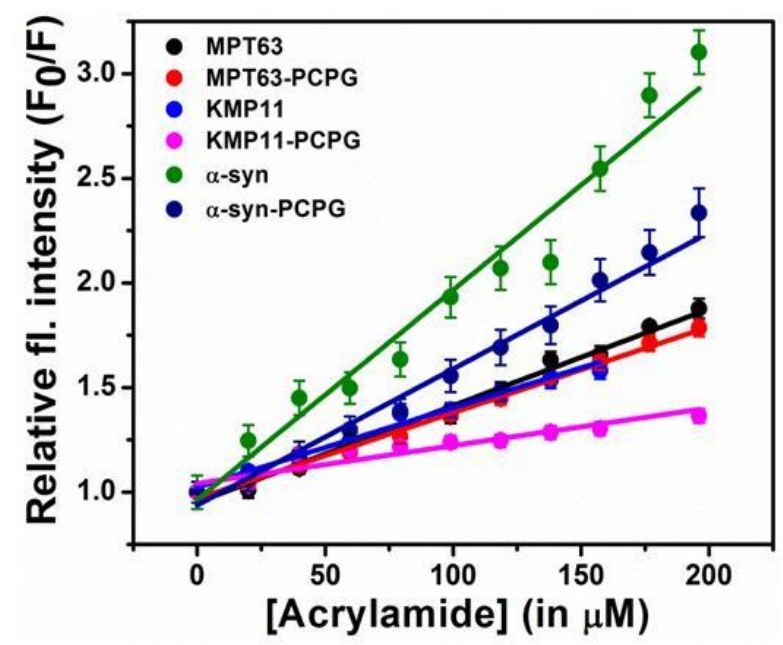

(c)

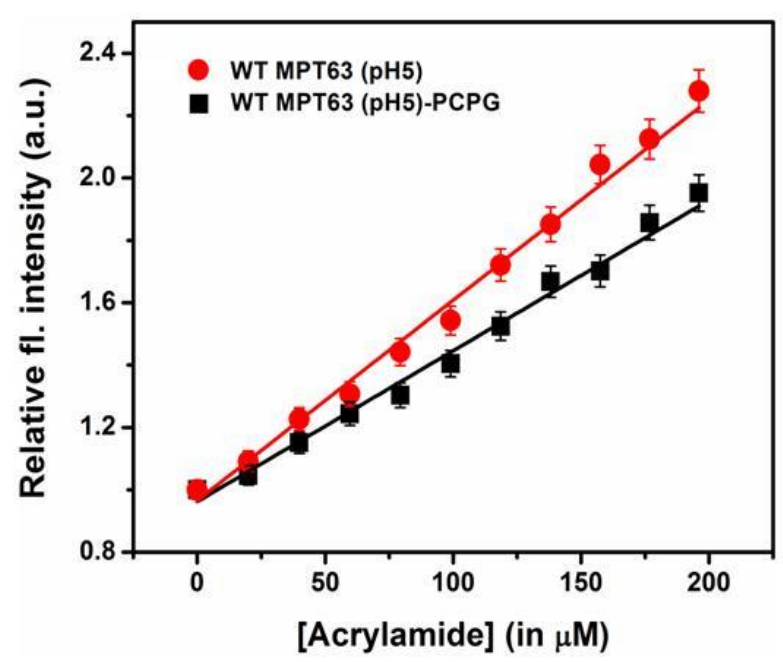

(b)

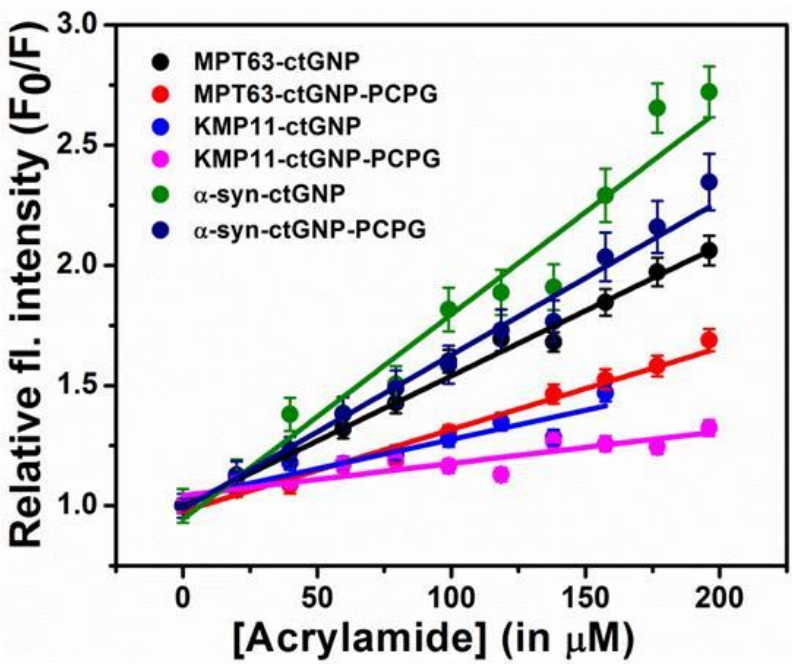

(d)

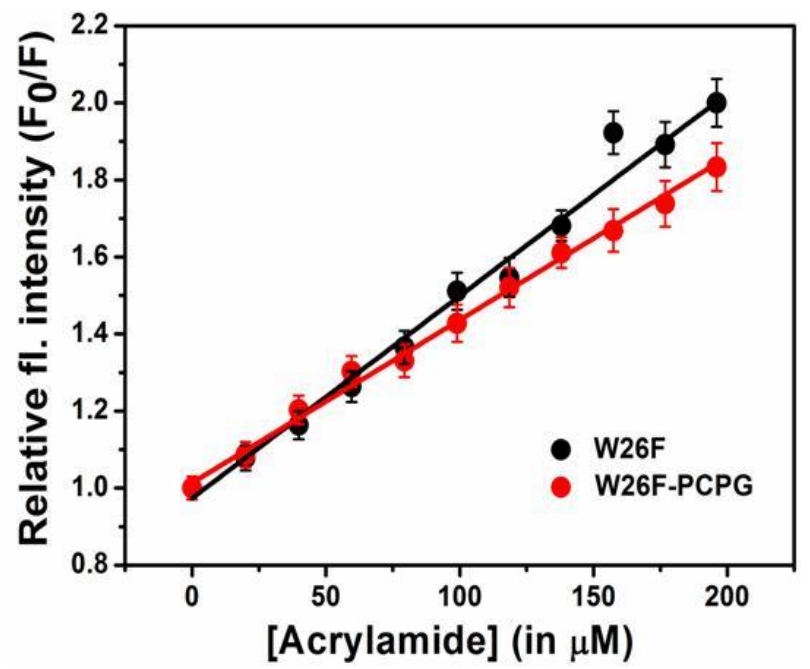

Figure S10. Acrylamide quenching experiments (a) Acrylamide-quenching plots $\left(\mathrm{F}_{0} / \mathrm{F}\right.$ vs acrylamide concentrations) of tryptophan and tyrosine residues of WT MPT63, KMP-11 (Y5W mutant has been used here) and $\alpha$-syn in membrane bound and unbound condition. (b) Quenching experiments of ct-GNP bound MPT63, $\alpha$-syn and KMP-11 in free and membrane bound conditions. (c) Quenching experiments of WT MPT63 at pH 5 in presence and absence of PCPG LUVs. (d) Acrylamide quenching plot of tryptophan residue of W26F in absence and presence of PCPG LUVs. pH of the solution was kept 7.5. 

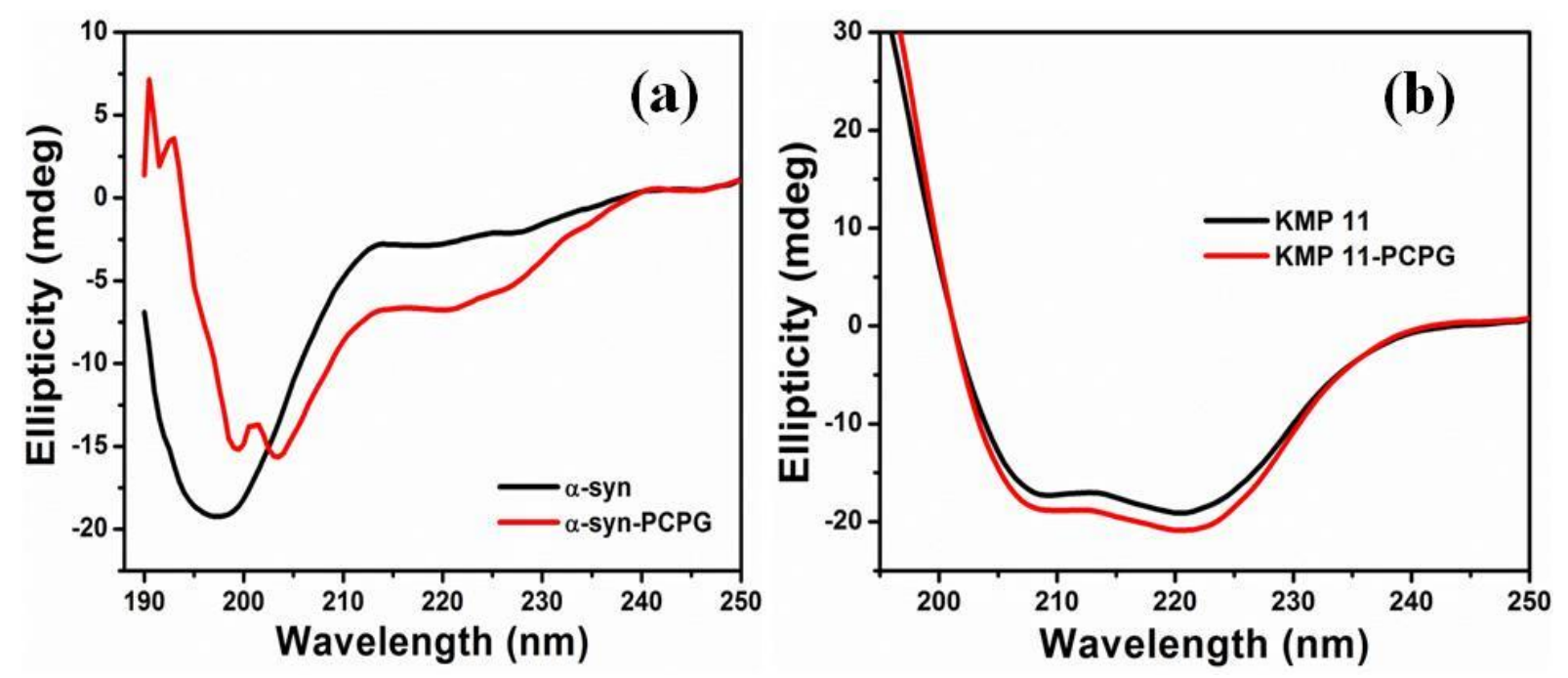

Figure S11. Structural changes of $\alpha$-syn and KMP-11 (a) Far-UV CD spectra of $\alpha$-syn in absence (black) and presence (red) of PCPG LUVs; (b) Far-UV CD spectra of KMP-11 in absence (black) and presence (red) of PCPG LUVs. 

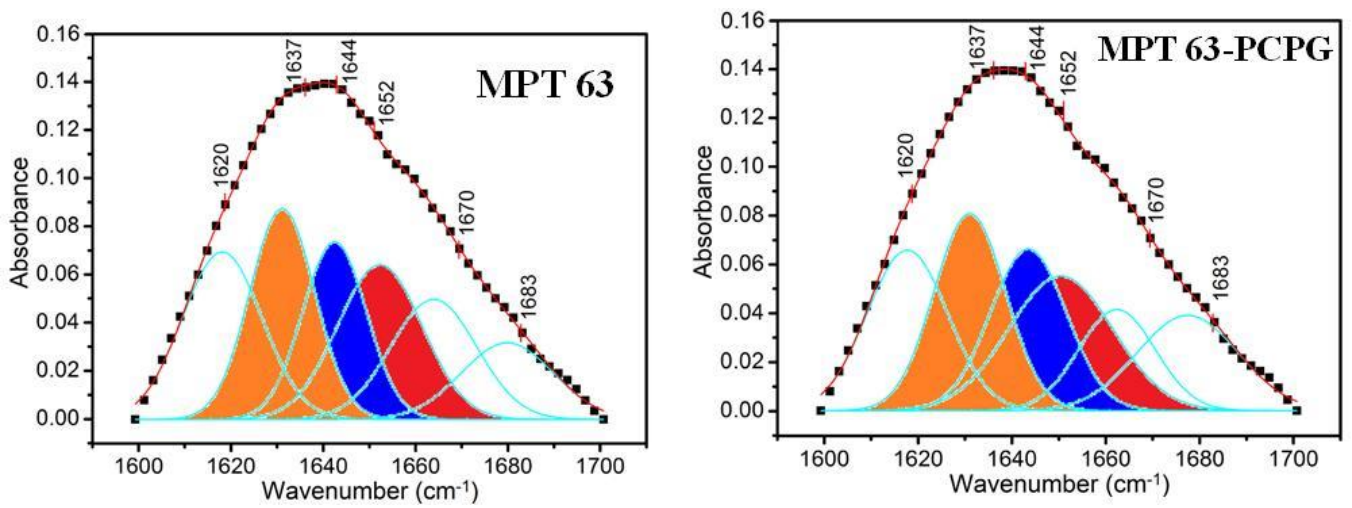

Figure S12. Deconvoluted FT-IR spectral signatures of amide-I region $(\mathrm{C}=\mathrm{O})$ of WT MPT63 in absence and presence of PCPG LUVs. Yellow region $\left(1637 \mathrm{~cm}^{-1}\right)$ denotes beta sheet; red region $\left(1652 \mathrm{~cm}^{-1}\right)$ indicates $\alpha$-helix and blue region $\left(1644 \mathrm{~cm}^{-1}\right)$ designates the disorder region of the proteins. 


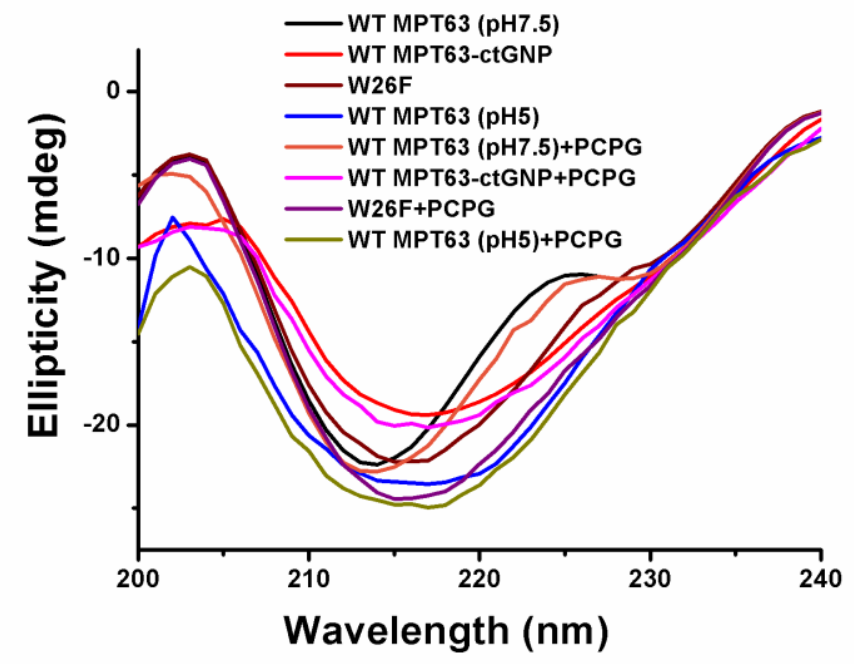

Figure S13. Far-UV CD spectra of WT MPT63 at pH 7.5, W26F, WT MPT63-ctGNP and WT MPT63 at pH 5 in absence and presence of PCPG LUVs. 

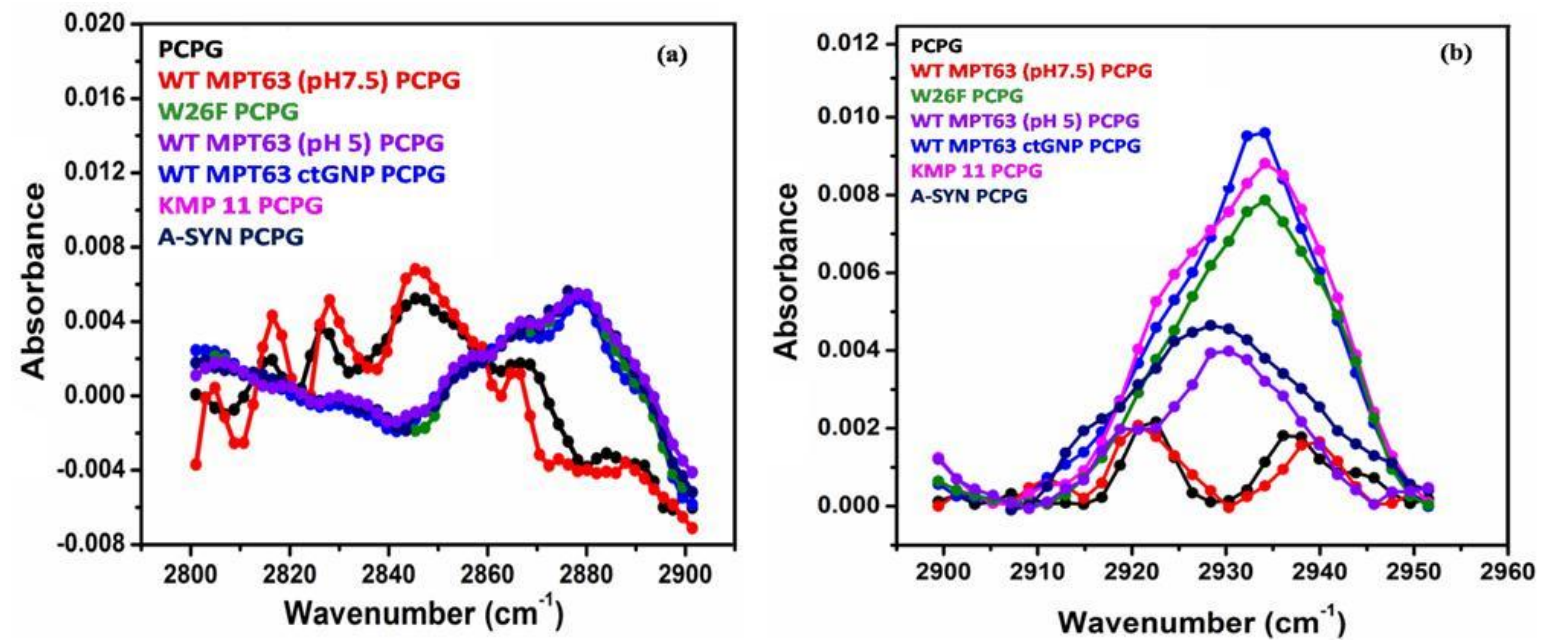

Figure S14. FTIR investigation on bilayer structure in presence of different protein species (a) Symmetric and (b) asymmetric $-\mathrm{CH}_{2}$ bond vibration of phospholipid membrane (PCPG LUVs) appearing at $2850 \mathrm{~cm}^{-1}$ and $2923 \mathrm{~cm}^{-1}$ respectively. All the FTIR signatures were collected in absence and presence of different protein species. 


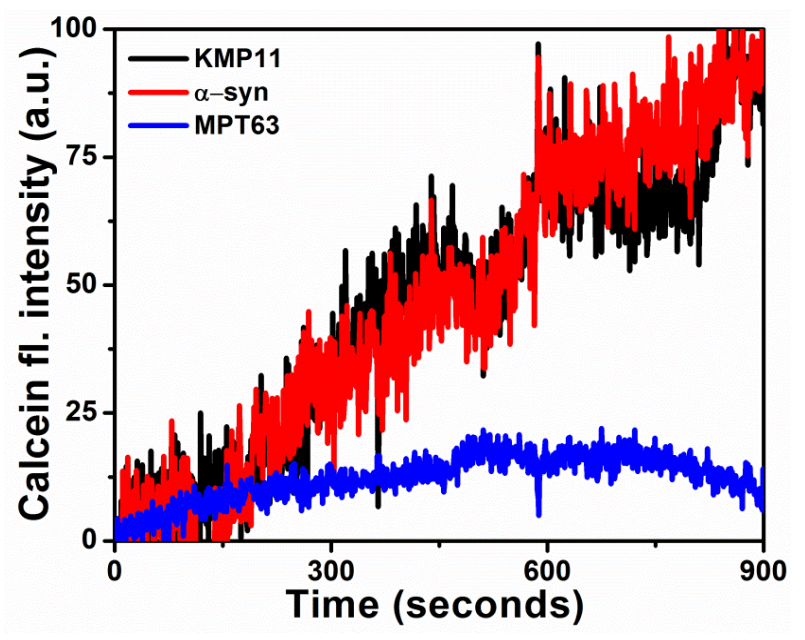

Figure S15. Vesicle dye leakage kinetics from PCPG for WT MPT63 at pH 7.5 (blue), $\alpha$-syn (red) and KMP-11 (black) are shown. 

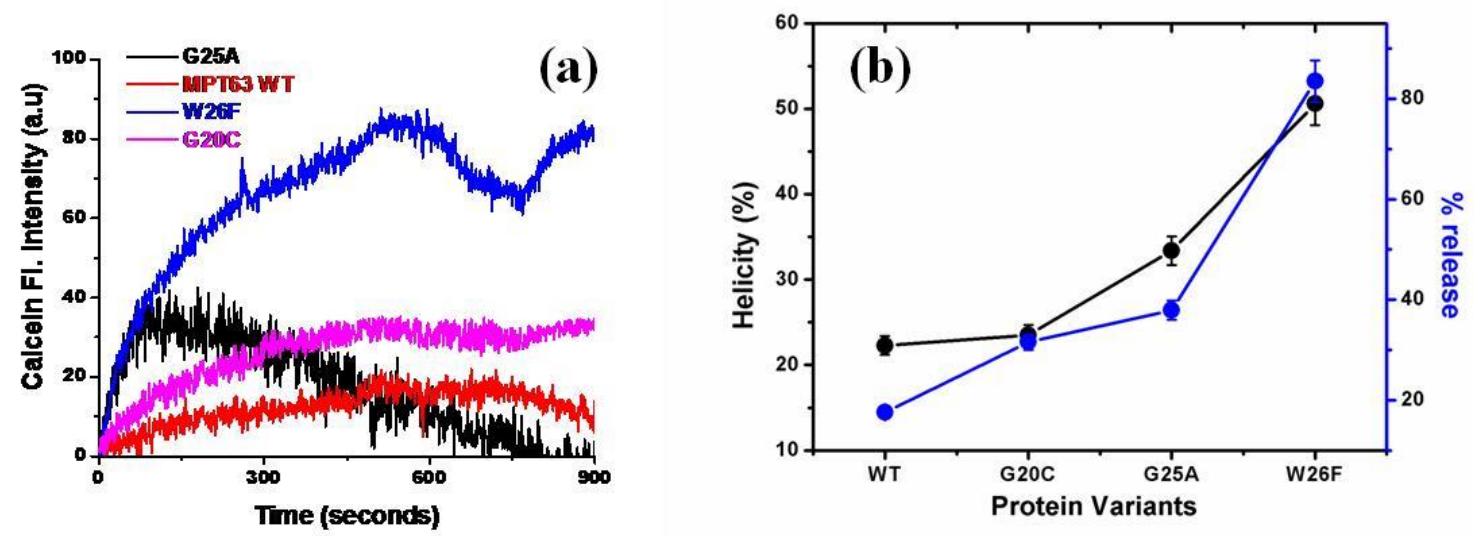

Figure S16.Vesicle dye leakage assay to probe the membrane pore formation; (a) Vesicle entrapped calcein leakage assay from PCPG LUVs for WT MPT63 and its different mutants (G25A, W26F, G20C) possessing different extent of helicity; (b) percentage helicity and dye release extent are plotted against different protein variants. Data revealed that extent of pore formation is proportional with that of the increase in helicity of MPT63. 


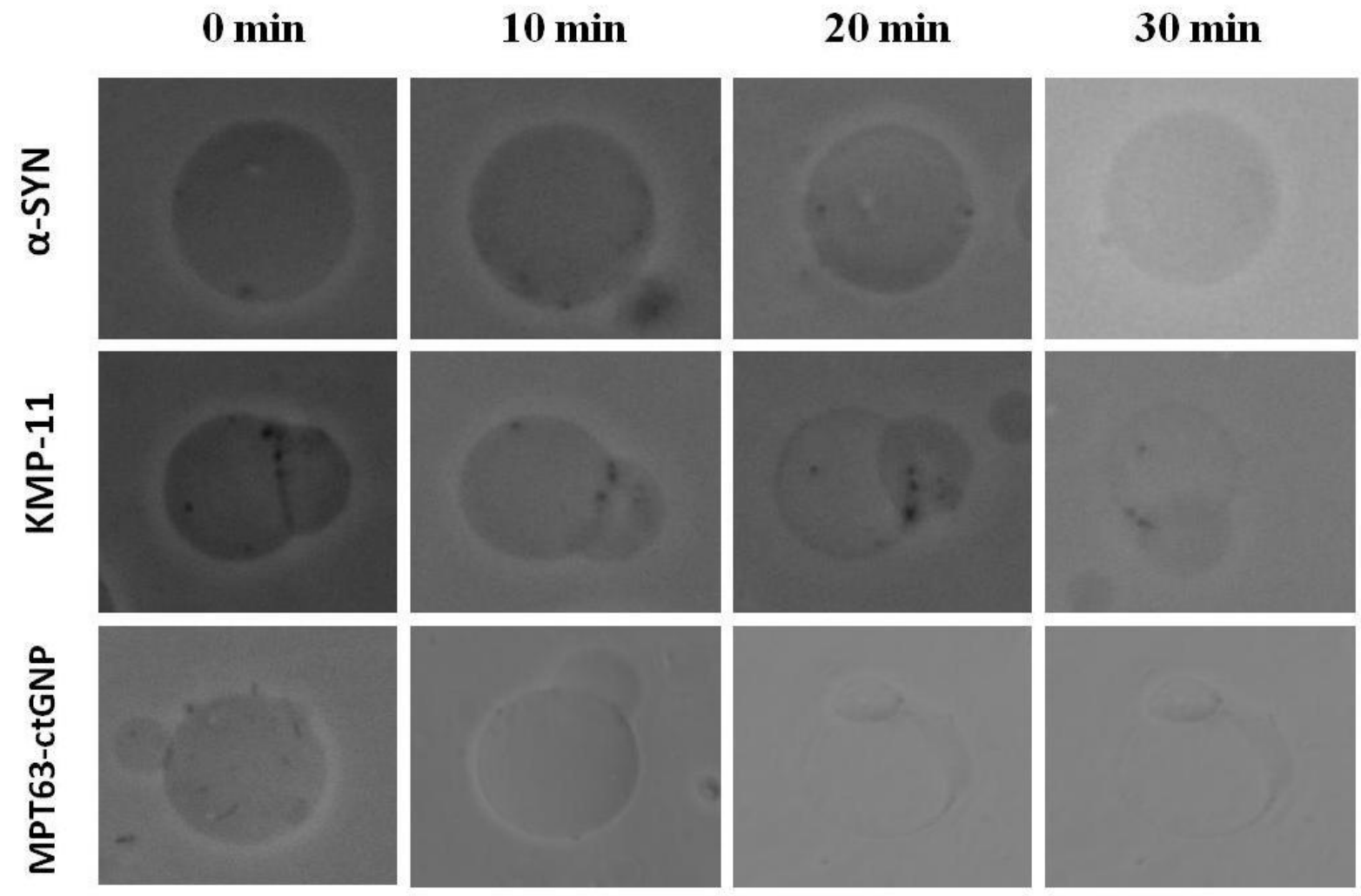

Figure S17. Single GUV method to measure the pore formation by protein species. The GUVs show different behavior due to the pore-formation process in vesicles with different protein variants outside ( $\alpha$-syn, KMP-11, WT MPT63-ctGNP at pH 7.5), as visible using phase-contrast microscopy. Loss of vesicle contrast with time was observed for all the samples. The sizes of vesicles were $\sim 34 \mu \mathrm{m}$. 


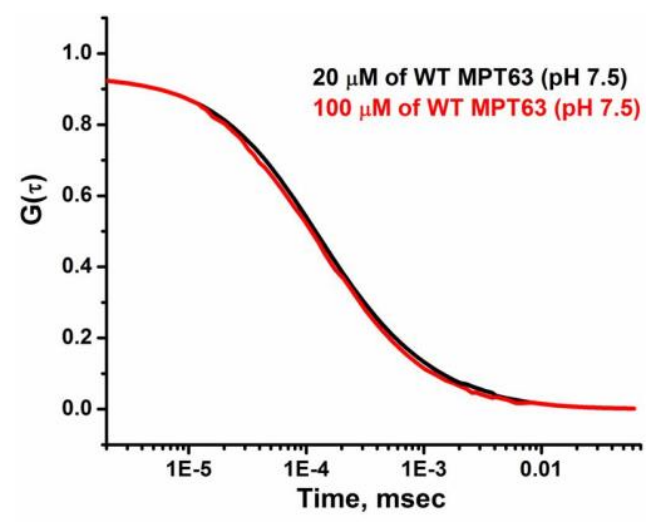

Figure S18. Correlation functions obtained for two different concentrations of MPT63 at $\mathrm{pH} 7.5$ ( $20 \mu \mathrm{M}$ in black and $100 \mu \mathrm{M}$ in red) indicating no appreciable change in diffusion parameters. 
(a)

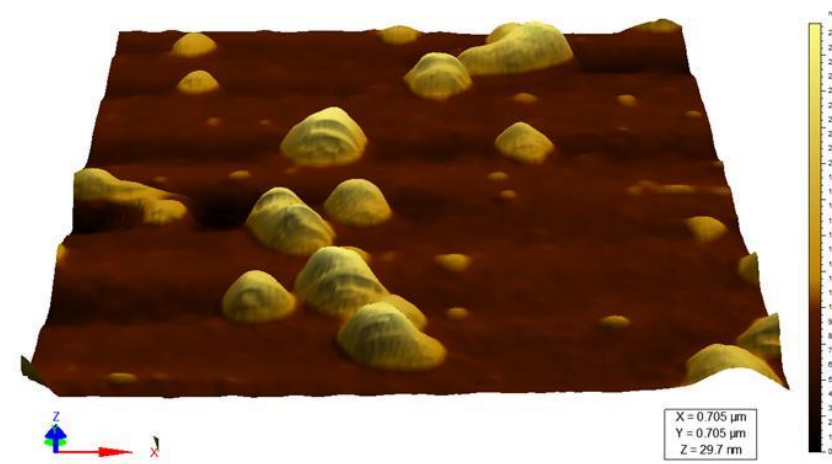

WT MPT63 at pH 5
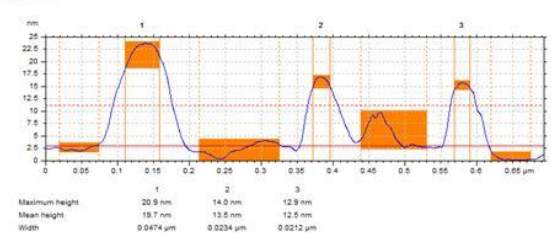

(b)

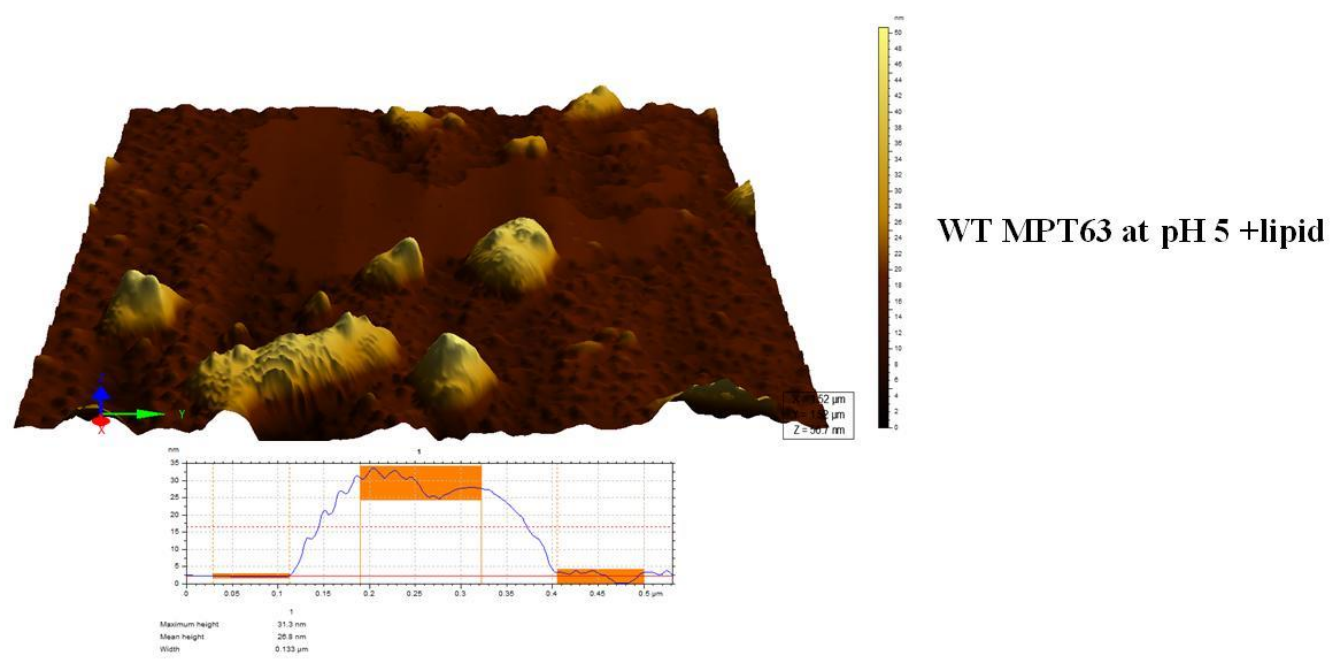

Figure S19: Detection of MPT63 oligomers using AFM analysis. 3D topography images of (a) oligomers formed by WT MPT63 at pH 5 and (b) oligomeric assemblies in presence of lipid vesicles. Height line profiles of oligomers and oligomeric assemblies are also given. ( $\mathrm{X}=$ distance; $\mathrm{Y}=$ Height $)$ 
(a)

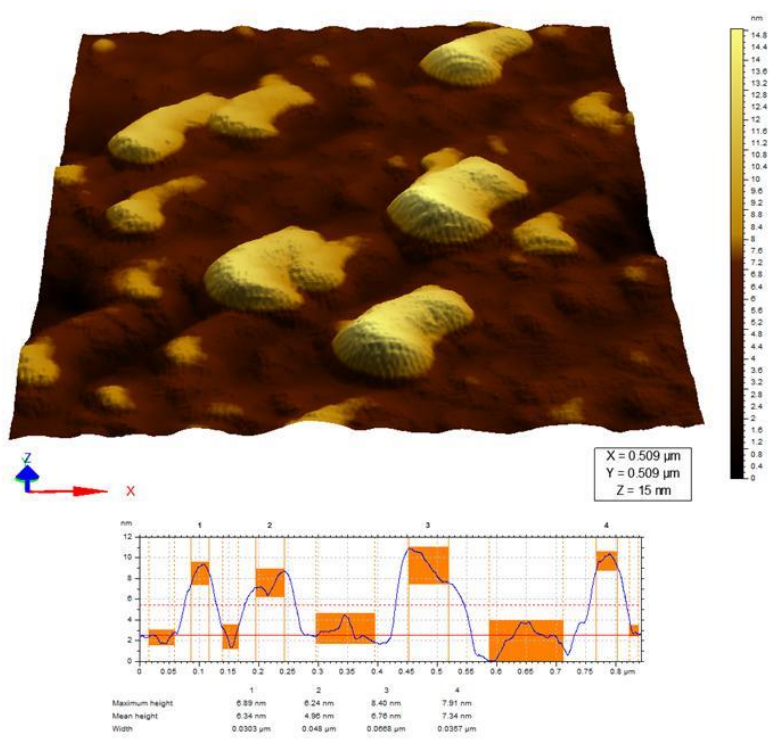

(b)

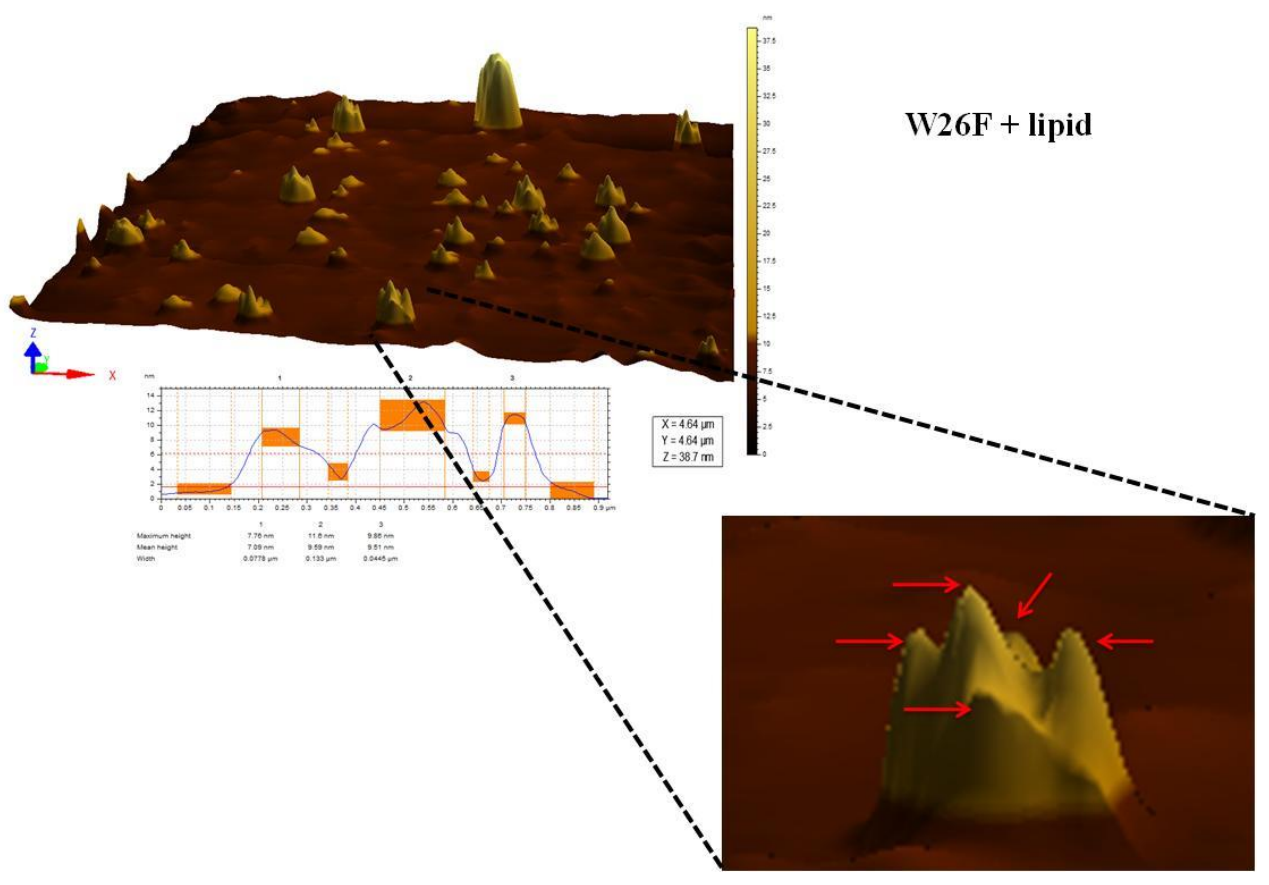

Figure S20: Detection of MPT63 oligomers using AFM analysis. 3D topography images of (a) oligomers formed by W26F and (b) oligomeric assemblies in presence of lipid vesicles. Height line profiles of oligomers and oligomeric assemblies are also given. (X=distance; Y=Height). 
(a)

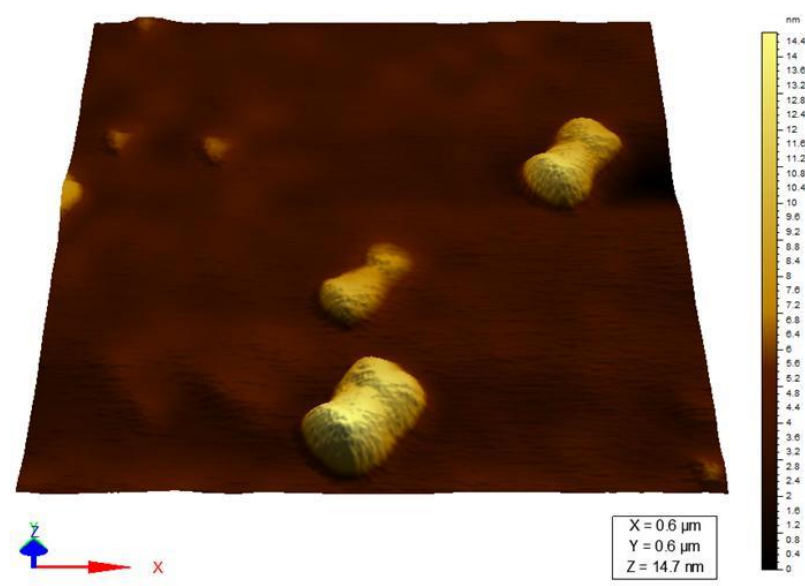

WT MPT63-ctGNP
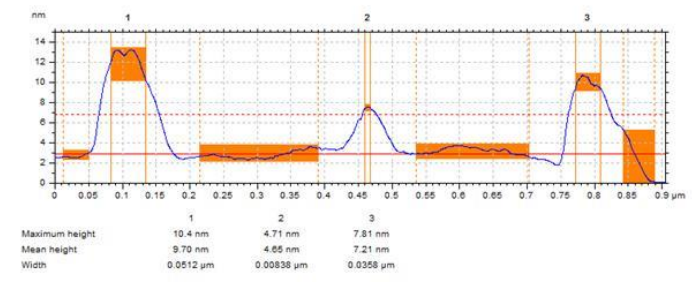

(b)

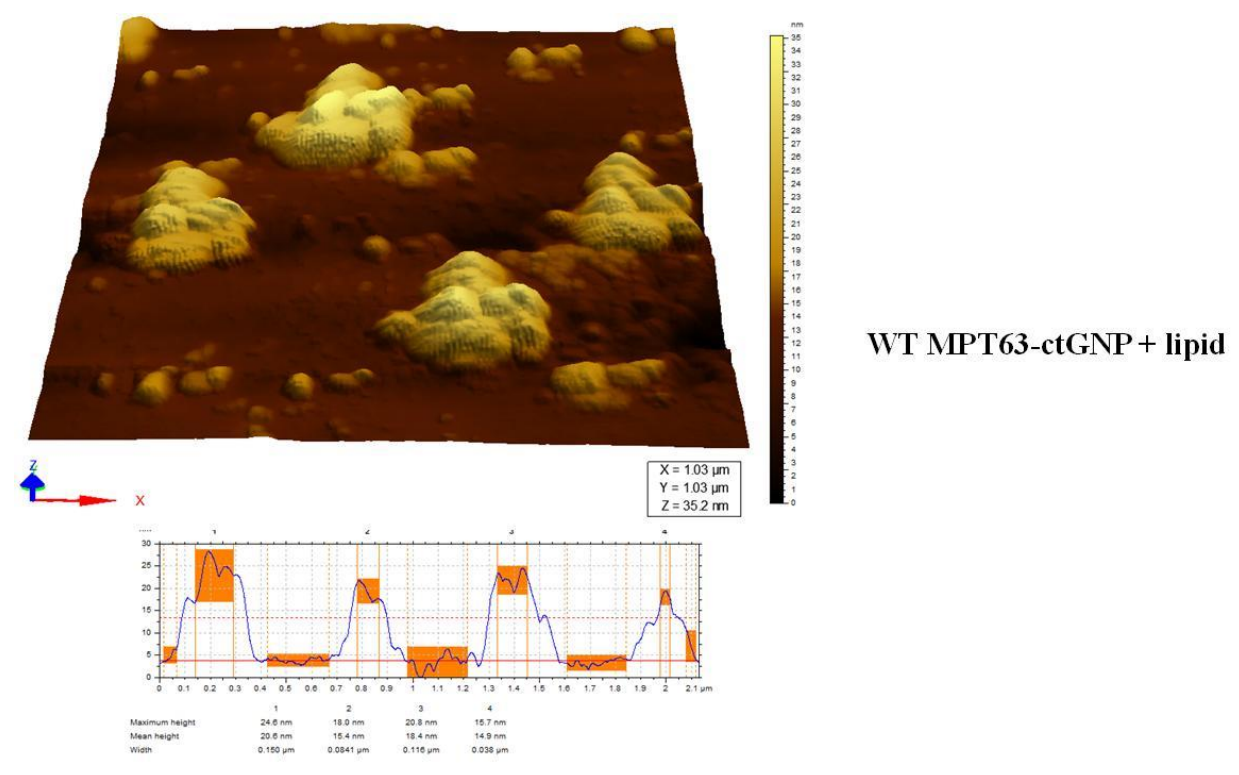

Figure S21: Detection of MPT63 oligomers using AFM analysis. 3D Topography images of (a) oligomers formed by WT MPT63-ctGNP and (b) oligomeric assemblies in presence of lipid vesicles. Height line profiles of oligomers and oligomeric assemblies are also given. ( $\mathrm{X}=$ distance; $\mathrm{Y}=$ Height $)$ 


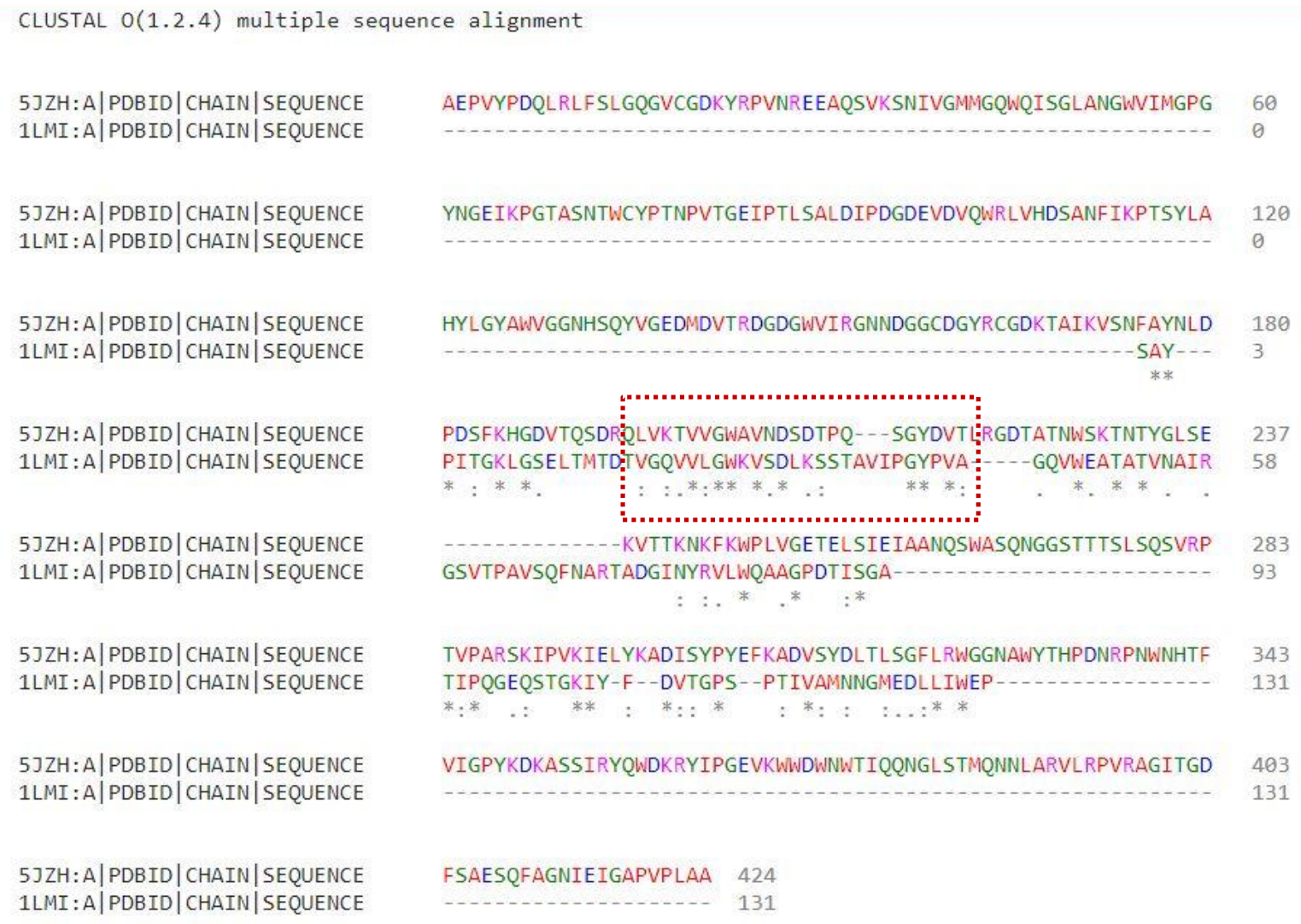

Figure S22: Sequence alignment of WT MPT63 (PDB ID: 1LMI) and aerolysin (PDB ID: 5JZH) shows $24.6 \%$ similarity with a conserved domain of 19-30 AA sequence stretch of MPT63. 
CLUSTAL O(1.2.4) multiple sequence alignment

1IAZ:A|PDBID|CHAIN|SEQUENCE $1 \mathrm{LMI}$ : A|PDBID|CHAIN|SEQUENCE

1IAZ: A|PDBID|CHAIN| SEQUENCE 1 LMI : A|PDBID|CHAIN | SEQUENCE

1IAZ:A|PDBID|CHAIN|SEQUENCE 1 LMI : A|PDBID|CHAIN | SEQUENCE

1IAZ:A|PDBID|CHAIN|SEQUENCE 1 LMI : A|PDBID|CHAIN |SEQUENCE

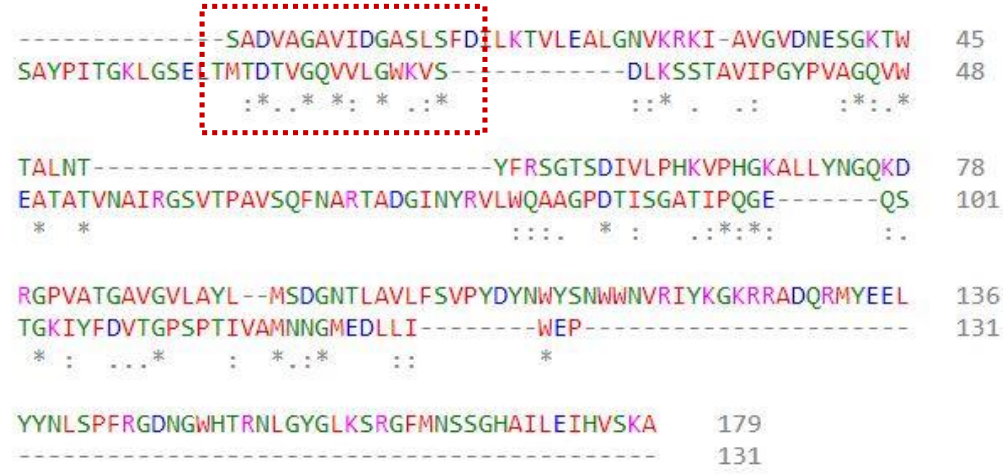

Figure S23: Sequence alignment of WT MPT63 (PDB ID: 1LMI) and equinatoxin (PDB ID: 1IAZ) shows $20.7 \%$ similarity with a conserved domain of 19-30 AA sequence stretch of MPT63. 


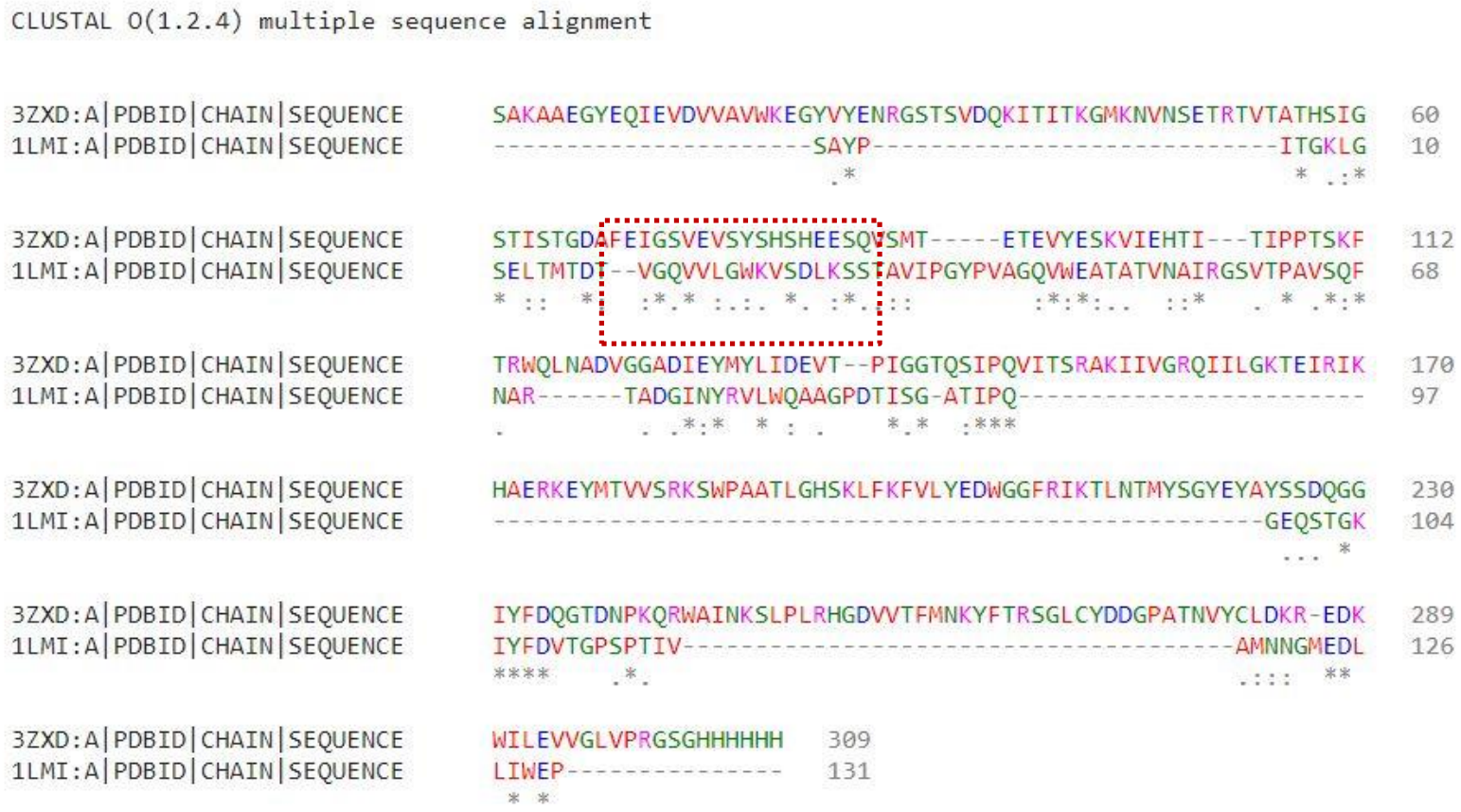

Figure S24: Sequence alignment of WT MPT63 (PDB ID:1LMI) and Lysenin (PDB ID: 3ZXD) shows $27.5 \%$ similarity with a conserved domain of 19-30 AA sequence stretch of MPT63. 


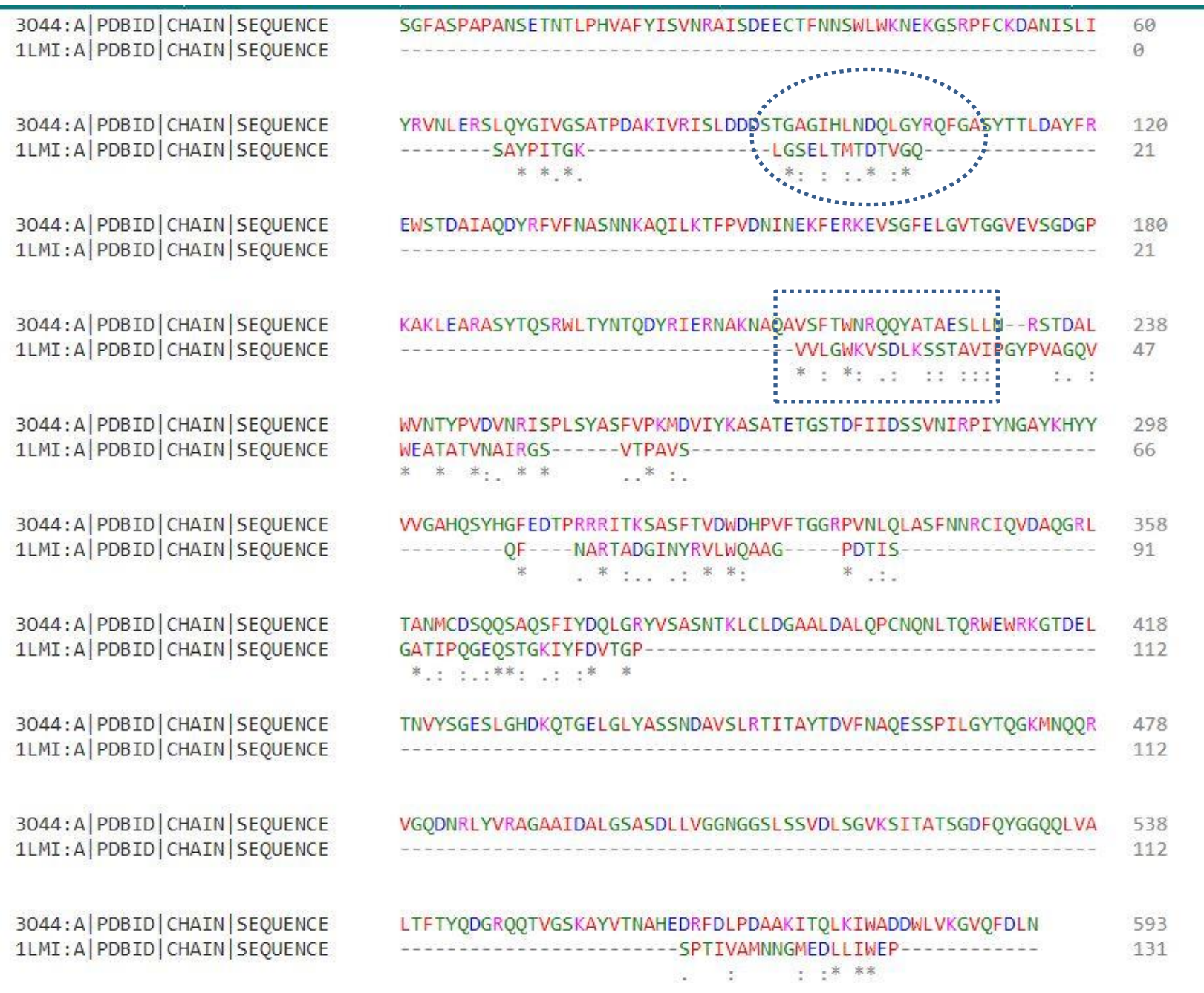

Figure S25: Sequence alignment of WT MPT63 (PDB ID: 1LMI) and Vibrio cholera cytolysin (PDB ID: 3O44) shows $20.9 \%$ similarity with a conserved domain of 19-30 AA sequence stretch of MPT63. 


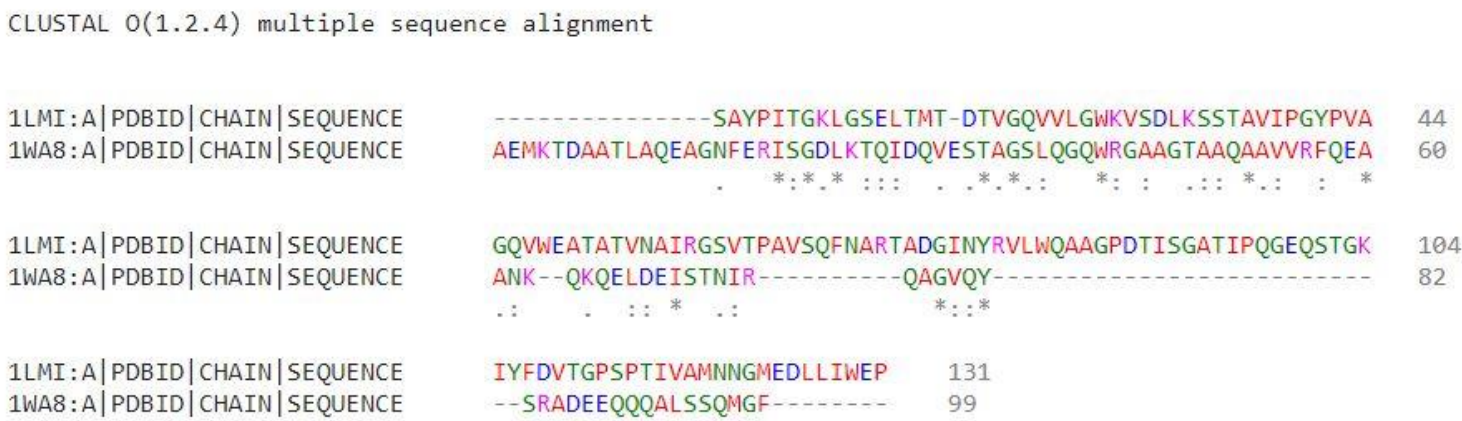

Figure S26: Sequence alignment of WT MPT63 (PDB ID: 1LMI) and ESAT 6 (PDB ID: 1WA8) shows $14.5 \%$ similarity with a conserved domain of 19-30 AA sequence stretch of MPT63. 


\section{References:}

1. Sannigrahi, A., Chall, S., Jawed, J. J., Kundu, A., Majumdar, S., and Chattopadhyay, K. (2018) Nanoparticle Induced Conformational Switch Between $\alpha$-Helix and $\beta$-Sheet Attenuates Immunogenic Response of MPT63, Langmuir 34, 8807-8817.

2. Basak, S., Prasad, G. R. K., Varkey, J., and Chattopadhyay, K. (2014) Early Sodium Dodecyl Sulfate Induced Collapse of $\alpha$-Synuclein Correlates with Its Amyloid Formation, ACS chemical neuroscience 6, 239-246.

3. Sannigrahi, A., Mullick, D., Sanyal, D., Sen, S., Maulik, U., and Chattopadhyay, K. (2019) Effect of Ergosterol on the Binding of KMP-11 with Phospholipid Membranes: Implications in Leishmaniasis, ACS Omega 4, 5155-5164.

4. Piella, J., Bastús, N. G., and Puntes, V. (2016) Size-Controlled Synthesis of Sub-10nanometer Citrate-Stabilized Gold Nanoparticles and Related Optical Properties, Chemistry of Materials 28, 1066-1075.

5. Sannigrahi, A., Maity, P., Karmakar, S., and Chattopadhyay, K. (2017) Interaction of KMP-11 with phospholipid membranes and its implications in leishmaniasis: effects of single tryptophan mutations and cholesterol, The Journal of Physical Chemistry B 121, 1824-1834.

6. Meleard, P., Bagatolli, L. A., and Pott, T. (2009) Giant unilamellar vesicle electroformation: From lipid mixtures to native membranes under physiological conditions, Methods in enzymology 465, 161-176.

7. Kong, J., and Yu, S. (2007) Fourier transform infrared spectroscopic analysis of protein secondary structures, Acta biochimica et biophysica Sinica 39, 549-559.

8. Yang, H., Yang, S., Kong, J., Dong, A., and Yu, S. (2015) Obtaining information about protein secondary structures in aqueous solution using Fourier transform IR spectroscopy, Nature protocols 10, 382.

9. Sannigrahi, A., Maity, P., Karmakar, S., and Chattopadhyay, K. (2017) Interaction of KMP-11 with phospholipid membranes and its implications in leishmaniasis: effects of 
single tryptophan mutations and cholesterol, The Journal of Physical Chemistry B 121, 1824-1834.

10. Nandi, I., Chall, S., Chowdhury, S., Mitra, T., Roy, S. S., and Chattopadhyay, K. (2018) Protein Fibril-Templated Biomimetic Synthesis of Highly Fluorescent Gold Nanoclusters and Their Applications in Cysteine Sensing, ACS omega 3, 7703-7714.

11. Allen, T. (1984) Calcein as a tool in liposome methodology, Liposome technology 3, 177182.

12. Kundu, A., Kundu, S., and Chattopadhyay, K. (2017) The presence of non native helical structure in the unfolding of a beta sheet protein MPT63, Protein Science 26, 536-549.

13. Chattopadhyay, K., Elson, E. L., and Frieden, C. (2005) The kinetics of conformational fluctuations in an unfolded protein measured by fluorescence methods, Proceedings of the National Academy of Sciences 102, 2385-2389.

14. Altman, S. A., Randers, L., and Rao, G. (1993) Comparison of trypan blue dye exclusion and fluorometric assays for mammalian cell viability determinations, Biotechnology progress 9, 671-674. 